\title{
A singleton NLR of recent origin causes hybrid necrosis
}

\section{in Arabidopsis thaliana}

A. Cristina Barragan', Maximilian Collenberg', Jinge Wang'2, Rachelle R.Q. Lee², Wei Yuan Cher², Fernando A. Rabanal', Haim Ashkenazy', Detlef Weigel'*, Eunyoung Chael,2*

*Corresponding authors: weigel@tue.mpg.de (D.W.), dbsce@nus.edu.sg (E.C.)

IDepartment of Molecular Biology, Max Planck Institute for Developmental Biology, 72076, Tübingen, Germany 2Department of Biological Sciences, National University of Singapore, I I7558, Singapore

\section{Keywords}

Hybrid incompatibility, autoimmunity, singleton NLR, DM/0, interchromosomal relocation

\section{Abstract}

Hybrid necrosis in plants arises from conflict between divergent alleles of immunity genes contributed by different parents, resulting in autoimmunity. We investigate a severe hybrid necrosis case in Arabidopsis thaliana, where the hybrid does not develop past the cotyledon stage and dies three weeks after sowing. Massive transcriptional changes take place in the hybrid, including the upregulation of most NLR disease resistance genes. This is due to an incompatible interaction between the singleton TIR-NLR gene DANGEROUS MIX 10 (DMI0), which was recently relocated from a larger NLR cluster, and an unlinked locus, DANGEROUS MIX I I $(D M I I)$. There are multiple DMIO allelic variants in the global $A$. thaliana population, several of which have premature stop codons. One of these, which has a truncated LRR domain, corresponds to the DMIO risk allele. The DMIO locus and the adjacent genomic region in the risk allele carriers are highly differentiated from those in the non-risk carriers in the global A. thaliana population, suggesting that this allele became geographically widespread only relatively recently. The DMII risk allele is much rarer and found only in two accessions from southwestern Spain - a region from which the DMIO risk haplotype is absent - indicating that the ranges of $D M I O$ and $D M I I$ risk alleles may be non-overlapping. 


\section{Introduction}

Hybrid necrosis, a predominant form of hybrid incompatibility, is caused by conflicting elements of the plant immune system originating from different parental accessions. These pairwise deleterious epistatic interactions usually involve at least one nucleotide binding site-leucine-rich repeat (NLR) protein (Bomblies et al. 2007; Alcázar et al. 2009; Yamamoto et al. 2010; Chae et al. 20l4; Sicard et al. 20I5; Deng et al. 2019). NLRs function as intracellular immune receptors homologous to NOD/CARD genes in animals, and play a major role in plant innate immunity (Maekawa et al. 20II; Jones et al. 2016). The constant co-evolutionary arms-race between plants and their pathogens has led to a high diversification of many elements of the plant immune system, including NLRs (Jones and Dangl 2006; Dodds and Rathjen 2010). Hybrid necrosis can be viewed as collateral damage resulting from excessive sequence diversity, a phenomenon that may limit the possible NLR allele combinations found in an individual plant (Chae et al. 20I4).

Plant NLRs are multidomain proteins usually composed of N-terminal Toll/interleukin-I receptor (TIR), coiledcoil (CC) or RESISTANCE TO POWDERY MILDEW 8 (RPW8) domains, a central nucleotide-binding site (NBS) and C-terminal leucine-rich repeats (LRRs) (Meyers et al. 2003; Shao et al. 2016). The N-terminal domain is usually thought to be involved in signal transduction, while the NBS domain can act as a molecular ON/OFF switch (Bentham et al. 2017). The LRR domain is highly variable and consists of multiple repeats of 20-30 amino acid stretches that are often responsible for direct or indirect pathogen effector recognition as well as NLR auto-inhibition (Ade et al. 2007; Krasileva et al. 20I0; Steinbrenner et al. 20I5).

Approximately half of all NLRs in a given A. thaliana accession are found in multi-gene clusters, which are unevenly distributed across the genome (Meyers et al. 2003; Van de Weyer et al. 2019). Tandem duplication events are common in NLR clusters, and duplicate genes are a major source of genetic variation, since they often experience relaxed selection and enable neofunctionalization (Ohno 1970; Force et al. 1999; Lynch and Conery 2000; Conant and Wolfe 2008). Sequence homogenization through intergenic exchange among cluster members is avoided when an NLR gene is translocated away from its original cluster to an unlinked genomic region, thereby preserving its original function or potentially developing a new one (Baumgarten et al. 2003; Leister 2004). For NLRs, neofunctionalization of duplicated or translocated genes can expand the repertoire of pathogen effectors an individual plant is able to recognize (Botella et al. 1998; Michelmore and Meyers 1998; Holub 200I; Kim et al. 2017).

Genome-wide analysis of structural variation across eight high-quality $A$. thaliana genomes identified rearrangement hot spots coinciding with numerous multi-gene NLR clusters (Jiao and Schneeberger 2020), including the previously described DANGEROUS MIX (DM) loci, which are causal for hybrid necrosis (Bomblies 
et al. 2007; Chae et al. 2014). This raises the possibility that accelerated evolution associated with genomic rearrangements contribute to the generation of incompatibility alleles, pointing to genomic architecture as a driver of hybrid incompatibility. So far, over a dozen NLR loci with hybrid necrosis alleles are known from multiple plant species, yet none of them is a singleton NLR, even though singletons account for about a quarter of NLRs in different species (Jacob et al. 2013). Most, but not all, well-characterized singleton NLRs, such as RPMI and RPS2 in A. thaliana, show ancient balanced polymorphisms that maintain active and inactive alleles at intermediate frequencies in natural metapopulations (Caicedo et al. 1999; Stahl et al. 1999; Mauricio et al. 2003; Allen et al. 2004; MacQueen et al. 2016). Thus, with less functional diversity, and beneficial alleles often being relatively common, one would indeed expect that singleton NLRs are underrepresented among hybrid necrosis loci.

Here, we are investigating a case of severe hybrid necrosis, where hybrid plants do not develop past the cotyledon stage, become necrotic, and die three weeks after sowing. Extensive transcriptional changes occur in the hybrid, including the induction of most NLR genes. Through a combination of QTL analysis and GWAS, we identified two new incompatibility loci, DANGEROUS MIX 10 (DMIO), a TIR-NLR on chromosome 5, and $D M I I$, an unlinked locus on chromosome I, as causal for incompatibility. DMIO is an unusual hybrid incompatibility locus because it is a singleton NLR that arose after $A$. thaliana speciation through interchromosomal transposition from the RLMI cluster, which confers resistance to blackleg disease in multiple Brassica species and A. thaliana (Richly et al. 2002; Staal et al. 2006; Guo et al. 20II). The causal allele has a premature stop codon that removes the C-terminal quarter of the protein, highlighting that substantial truncations of the coding region do not necessarily indicate loss of function.

\section{Results}

\section{A particularly severe case of hybrid necrosis: Cdm-0 x TueScha-9}

Eighty A. thaliana accessions have previously been intercrossed with the goal of identifying hybrid incompatibility hot spots (Chae et al. 2014). A particularly severe case was observed in the crosses between $\mathrm{Cdm}-0$ and five other accessions: TueScha-9, Yeg-I, Bak-2, ICE2I and Leo-I. The $F_{I}$ progeny of these two parents did not develop past the cotyledon stage, even at temperatures that suppress hybrid necrosis in most other cases (Chae et al. 20l4), and severe necrosis developed during the second week after sowing, followed by complete withering in the third week (Fig I A).

To obtain insights into the transcriptional changes in the hybrid, we performed RNA-seq on the parental accessions Cdm-0 and TueScha-9, as well as in $F_{1}$ hybrid plants 10 days after germination, when the hybrid was 
already slightly stunted, but before there were visible signs of necrosis (Fig IB). We observed massive transcriptional changes, in which around half of all 20,000 detectable genes (Fig SIA) were differentially expressed in the hybrid when compared to either parent (Fig IC, SIB, Table SI). This represents one third of the entire A. thaliana transcriptome (Klepikova et al. 2016). A principal component analysis (PCA) showed that most of the variance in gene expression is driven by the difference between the parents and the hybrid (PCI: 83 \%) (Fig ID). In addition, we generated in silico hybrids (see Methods) and compared these with the biological $F_{1}$ hybrids through a PCA. This confirmed that gene expression in the $F_{1}$ hybrid is not an additive result of expression in the two parental accessions (Fig SIC). Next, we carried out a Gene Ontology (GO) analysis using the top I,000 differentially expressed genes (DEGs) between the $F_{1}$ hybrid and the MPV (Table S2). "Defense response" and "salicylic acid biosynthesis" were the categories with the highest number of DEGs in the hybrid versus MPV comparison (Fig IE, Table S2).

Since the $F_{1}$ hybrid displayed signs of an increased pathogen defense response, we analyzed the expression of a set of marker genes for defense-associated phytohormones such as jasmonic acid (JA), salicylic acid (SA) and ethylene (ET) (Papadopoulou et al. 2018), as well as early pathogen response genes induced by both cell surface receptors and NLRs (Ding et al. 2020) (Table S3). Genes involved in SA biosynthesis and signaling, such as EDSI, ICSI, EDS5, PAD4, PBS3, CBP60 and FMOI, were strongly overexpressed in $F_{1}$ hybrid plants, in concordance with the GO analysis, as was the SA-induced camalexin biosynthesis gene CYP7IA/3. The expression of genes encoding transcription factors WRKY46 and WRKY5I and of the late immune response gene $P R I$ was also increased in the hybrid (Fig IF, Table S3). In contrast, the expression of genes required for JA-mediated resistance, such as MYC2 or DDE2, or genes involved in ET signaling, such as ETRI, ERFI and EIN3, changed to a lesser extent in the $F_{1}$ hybrid, similar to control genes UBQIO and TUB2 (Fig IF, Table S3).

Since an increase in NLR expression has been linked to autoimmunity (Stokes et al. 2002; Mackey et al. 2003; Palma et al. 2010; Lai and Eulgem 2018), and since some NLRs are upregulated when SA levels rise (Shirano et al. 2002; Yang and Hua 2004; Tan et al. 2007; Mohr et al. 2010; MacQueen and Bergelson 2016), we set out to investigate NLR expression levels in the hybrid. Out of a set of 166 NLRs found in the Col-0 genome, I50 were expressed in at least one of the three genotypes studied, and 128 were significantly $\left(\mid \log { }_{2}\right.$ FoldChange $\mid>$, padj value < 0.0I) differentially expressed in at least one genotype comparison (Fig S2D, Table S4). From these 128 NLRs, all but one were differentially expressed when comparing the hybrid with either parental accession (Fig SID). NLRs were mostly upregulated in the $F_{1}$ hybrid: of the 95 NLRs with significant expression changes in the hybrid versus the MPV, all but three were overexpressed (Fig IG, SIE, Table SI). When the $F_{1}$ hybrid was compared to the parents, the expression of individual NLRs largely followed the same pattern (Fig S IE-G), this was not the case when comparing the two parents (Fig S I H). The fraction of 
bioRxiv preprint doi: https://doi.org/10.1101/2020.05.18.101451; this version posted May 20, 2020. The copyright holder for this preprint (which

was not certified by peer review) is the author/funder, who has granted bioRxiv a license to display the preprint in perpetuity. It is made available under aCC-BY 4.0 International license.

Barragan et al.

Relocated singleton NLR and hybrid necrosis

genes overexpressed in the $F_{1}$ hybrid was similar for the different NLR classes as well as between singleton and clustered NLRs (Fig IG, S IF-H, Table S3).

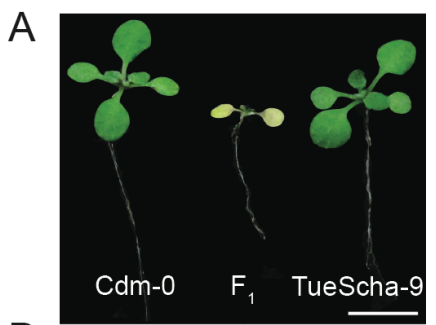

D

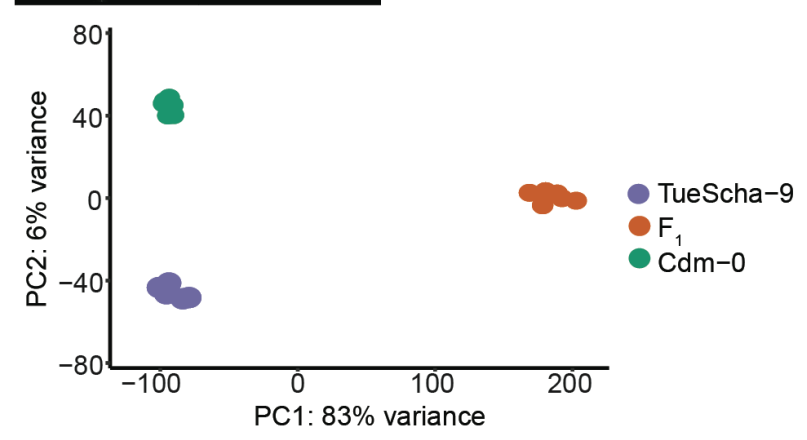

F

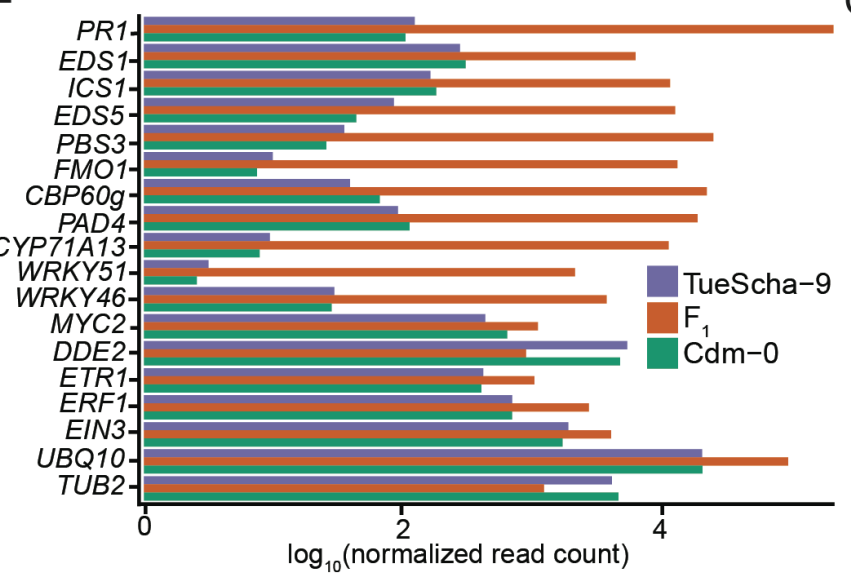

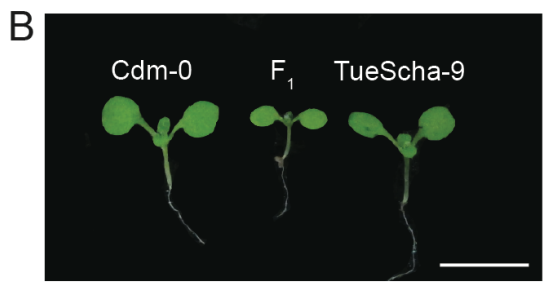

$\mathrm{E}$

C

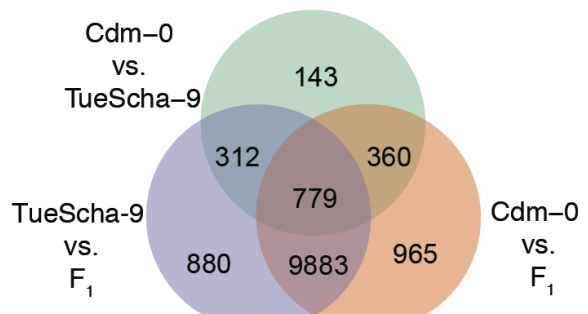

G

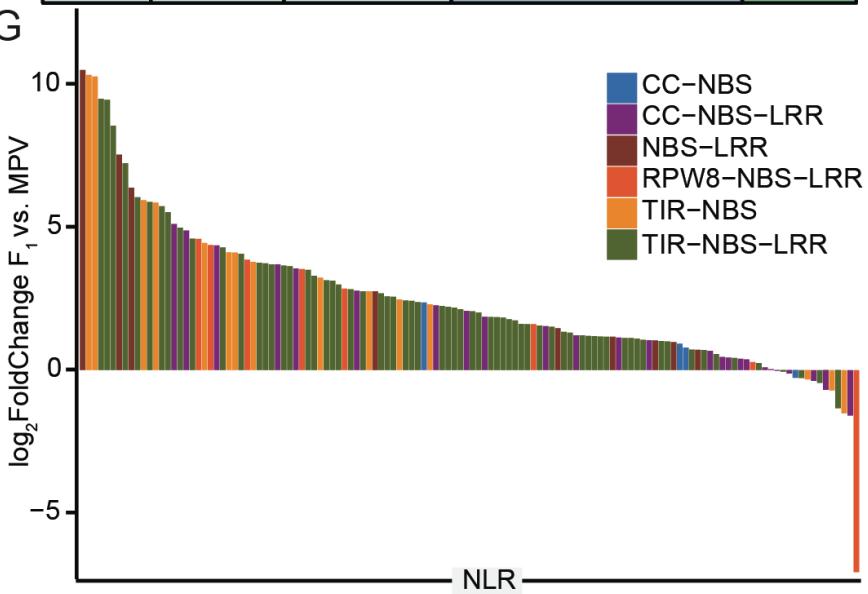

Fig I. RNA-seq analysis of Cdm-0 x TueScha-9 hybrids. A. At 21 days, the Cdm- $0 \times$ TueScha-9 $F_{1}$ hybrid is necrotic. Plants were grown at $16^{\circ} \mathrm{C}$. Scale bar represents $1 \mathrm{~cm}$. B. Examples of a 10-day old Cdm-0 0 TueScha-9 $F_{1}$ hybrid and parental accessions harvested for RNA-seq. Plants were grown at $23^{\circ} \mathrm{C}$. Scale bar represents $1 \mathrm{~cm}$. C. Intersection of DEGs between the $F_{1}$ hybrid and parents. D. PCA of gene expression values. The main variance is between the $F_{1}$ hybrid and parents. Each dot indicates one biological replicate, with six per genotype. E. REVIGO Gene Ontology treemap. Size of the square represents $-\log _{10}\left(p\right.$ value) of each GO term. F. - $\log _{10}$ (normalized read count) of defenserelated marker genes of the hybrid and the parents. G. NLR expression changes between the $F_{1}$ hybrid and the MPV, with I 28 significantly ( $\mid \log _{2}$ FoldChange| $>$ I, padj value $<0.0$ I) differentially expressed in at least one genotype comparison.

\section{QTL mapping of DMIO and DMII in a triple-hybrid cross}

Having found that a very large fraction of NLR genes is upregulated in the Cdm-0 $\times$ TueScha- 9 hybrid, we wondered whether hybrid necrosis in this case was due to global NLR regulators (Li et al. 2009; Zhai et al. 20II; Shivaprasad et al. 2012; Gloggnitzer et al. 2014; Sicard et al. 20I5), or to NLRs, as in other hybrid 
necrosis cases. We therefore proceeded to map the underlying causal loci via quantitative trait locus (QTL) analysis. Since the $F_{1}$ hybrid seedlings died very young, we could not directly generate a segregating $F_{2}$ mapping population (Bomblies et al. 2007; Chae et al. 20I4; Barragan et al. 2019). Instead, we designed a triple-hybrid cross (Cooper et al. 2019) and first generated two sets of heterozygous plants by crossing Cdm-0 and TueScha-9 separately to a third, innocuous background, the Col-0 reference accession. We then intercrossed these $\mathrm{Cdm}-0 / \mathrm{Col}-0$ and TueScha-9/Col-0 plants (Fig 2A). In the resulting pseudo- $\mathrm{F}_{2}$ generation, we collected both normal and necrotic plants and individually genotyped them by RAD-seq (Rowan et al. 2017). For QTL mapping, we focused on polymorphic markers between $\mathrm{Cdm}-0$ and TueScha-9, including markers overlapping with the Col-0 reference (Fig 2B), and also analyzed polymorphic markers for each accession independently (Fig S2A, B). We identified two genomic regions that interact epistatically to cause the severe hybrid necrosis phenotype. We called the QTL on chromosome 5 (23.35 to $24.45 \mathrm{Mb}$ ) DMI0, and the QTL on chromosome I (2I.55 to $22.18 \mathrm{Mb}$ ) DMII. Both intervals contained NLRs but no clear candidates for global NLR regulators, so we chose to focus on NLR genes. In the DMIO mapping interval, one NLR was present, At5g58I20, while the DMII interval was NLR-rich and encompassed 10 NLRs in Col-0 (Table S5). Loci in the interval included the highly polymorphic RPP7 cluster of CC-NLR genes (McDowell et al. 2000; Guo et al. 20 I I; Li et al. 2020), as well as the two CC-NLR singleton genes, CW9 (At lg59620) and At lg59780 (Meyers et al. 2003). To identify potential differences between Col-0 and Cdm-0 in the DMII interval, we generated a PacBio long-read-based genome assembly of this accession (Table S6). Notably, most chromosome arms were assembled in single contigs, including the long arm of chromosome I, where the DMII mapping interval is located (Fig S3). Since at the time the full Cdm-0 annotation was not yet available, we manually annotated homologs of NLR genes corresponding to the genomic region that spans from Atlg565I0 to Atlg64070 in Col-0, which includes the DMII mapping interval as well as neighboring NLRs. Like Col-0, Cdm-0 carries groups of both clustered and singleton NLRs, adding up to a total of 21 NLRs, compared to 28 NLRs in Col-0 (Fig 2C, Table S5).

To pinpoint DMII candidate genes, we sought to identify additional accessions that had similar alleles as Cdm0 at DMII candidate loci by creating Neighbor-Joining (NJ) trees (Fig S2C) and PCA plots (Fig S2D, Table S7), using sequences from the I00I Genomes Project (I00I Genomes Consortium 20I6). IP-Cum-I was the accession most similar to $\mathrm{Cdm}-0$ for the whole DMII mapping interval, and when we crossed it to TueScha-9, Cdm-0 x TueScha-9-like hybrid necrosis was observed (Fig 2D). Eleven other accessions that were less closely related to $\mathrm{Cdm}-0$ in this genomic interval did not produce necrotic $\mathrm{F}_{1}$ hybrids (Table S7). Because accessions Istisu-I and ICEI34, like Cdm-0, lack a transposable element that is present in most RPP7 (Atlg68602) alleles (Tsuchiya and Eulgem 2013), we also crossed these two accessions to TueScha-9, but no hybrid necrosis was observed (Table S7). Artificial miRNAs (amiRNAs) (Schwab et al. 2006) targeting 
bioRxiv preprint doi: https://doi.org/10.1101/2020.05.18.101451; this version posted May 20, 2020. The copyright holder for this preprint (which was not certified by peer review) is the author/funder, who has granted bioRxiv a license to display the preprint in perpetuity. It is made available under aCC-BY 4.0 International license.

Barragan et al. Relocated singleton NLR and hybrid necrosis

different members of the RPP7 cluster were previously designed to perform rescue experiments (Chae et al. 2014; Barragan et al. 2019); although predicted to target all members of the Cdm-0 RPP7 cluster, neither these nor amiRNAs targeting CW9Cdm-0 or At I g59780Cdm-0 suppressed hybrid necrosis (Table S8). Lastly, a genomic CW9Cdm-0 fragment was unable to induce hybrid necrosis when introduced into TueScha-9 (Table S I 5).
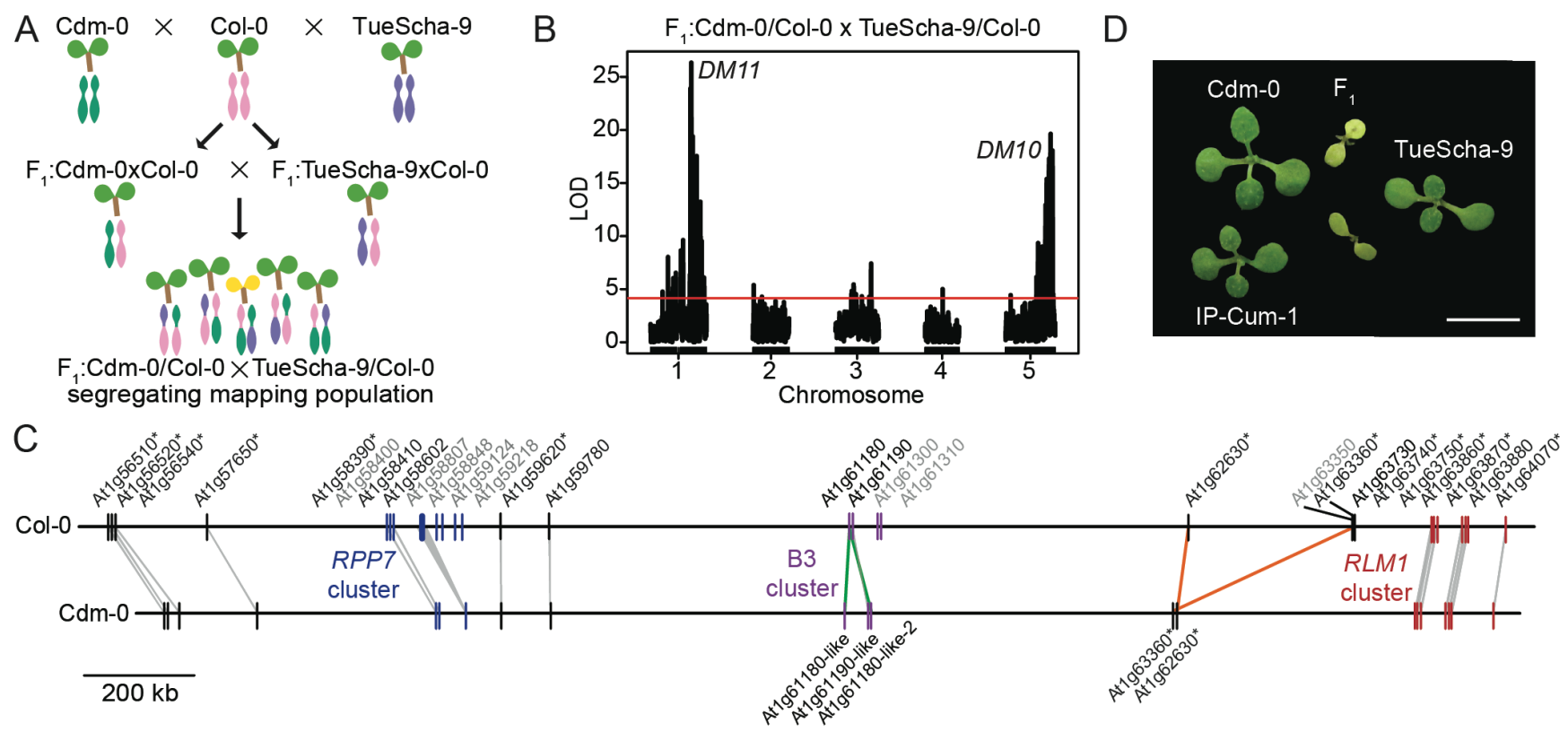

Fig 2. QTL mapping with a triple-hybrid cross. A. Creation of a Cdm- $0 \times$ TueScha- 9 mapping population. B. QTL analysis from polymorphic Cdm-0 and TueScha-9 markers. QTL peaks are found on chromosome 5 (23.35-24.45 $\mathrm{Mb}), \mathrm{DM} / 0$, and chromosome I (2I.98-22.04 Mb), DMII. The horizontal lines indicate 0.05 significance threshold established with I,000 permutations. C. Comparison and distribution of candidate DM I I NLR genes between At Ig565I0 and At Ig64070 on chromosome I. Gene IDs in grey are present in Col-0 but not in Cdm-0, gene duplications are marked in green and inversion events in orange. Asterisks indicate significant ( $\mid \log _{2}$ FoldChange|>I, padj value < 0.0I) gene expression changes in the $F_{1}$ hybrid when compared to the MPV. D. Cdm-0 $\times$ TueScha-9 and IP-Cum-I $x$ TueScha- 9 hybrids. Plants are two weeks old and were grown at $16^{\circ} \mathrm{C}$. Scale bar represents $\mathrm{I} \mathrm{cm}$.

Being aware that the precision of QTL mapping in NLR-rich regions can be affected by structural variation, we also tested NLRs adjacent to the DMI I mapping interval. The RLM I cluster is highly similar among Cdm- 0 and IP-Cum-I, both of which carry the causal DMII allele in addition, some cluster members show an increased expression in the $F_{1}$ hybrid, which is sometimes the case for causal NLRs (Bomblies et al. 2007) (Fig S2E). We therefore tested six of the seven RLMI cluster members via Nicotiana benthamiana co-expression with DMIOTuescha-9 (see Fig 4 for cloning of causal DMIO allele), but none induced a hypersensitive response (HR) (Table S5). Six accessions with a similar RLMI locus to that of Cdm-0 and IP-Cum-I were crossed with TueScha-9, but no necrosis was observed (Table S7). Finally, because At g57650 was strongly upregulated among DMII NLR candidate genes, we tested it with DMIOTueScha-9 in N. benthamiana, but again no HR was observed (Fig S2E, Table S4, S5). This may indicate that DMII is either an NLR that was not tested, or not an NLR at all. Note that some Col-0 NLRs that had no homologs in the interval from At lg565I0 to At lg64070 
bioRxiv preprint doi: https://doi.org/10.1101/2020.05.18.101451; this version posted May 20, 2020. The copyright holder for this preprint (which was not certified by peer review) is the author/funder, who has granted bioRxiv a license to display the preprint in perpetuity. It is made available under aCC-BY 4.0 International license.

Barragan et al.

Relocated singleton NLR and hybrid necrosis

in Cdm-0 attracted nonspecific RNA-seq reads, most likely because there are homologs elsewhere in the Cdm0 genome (Table S5).

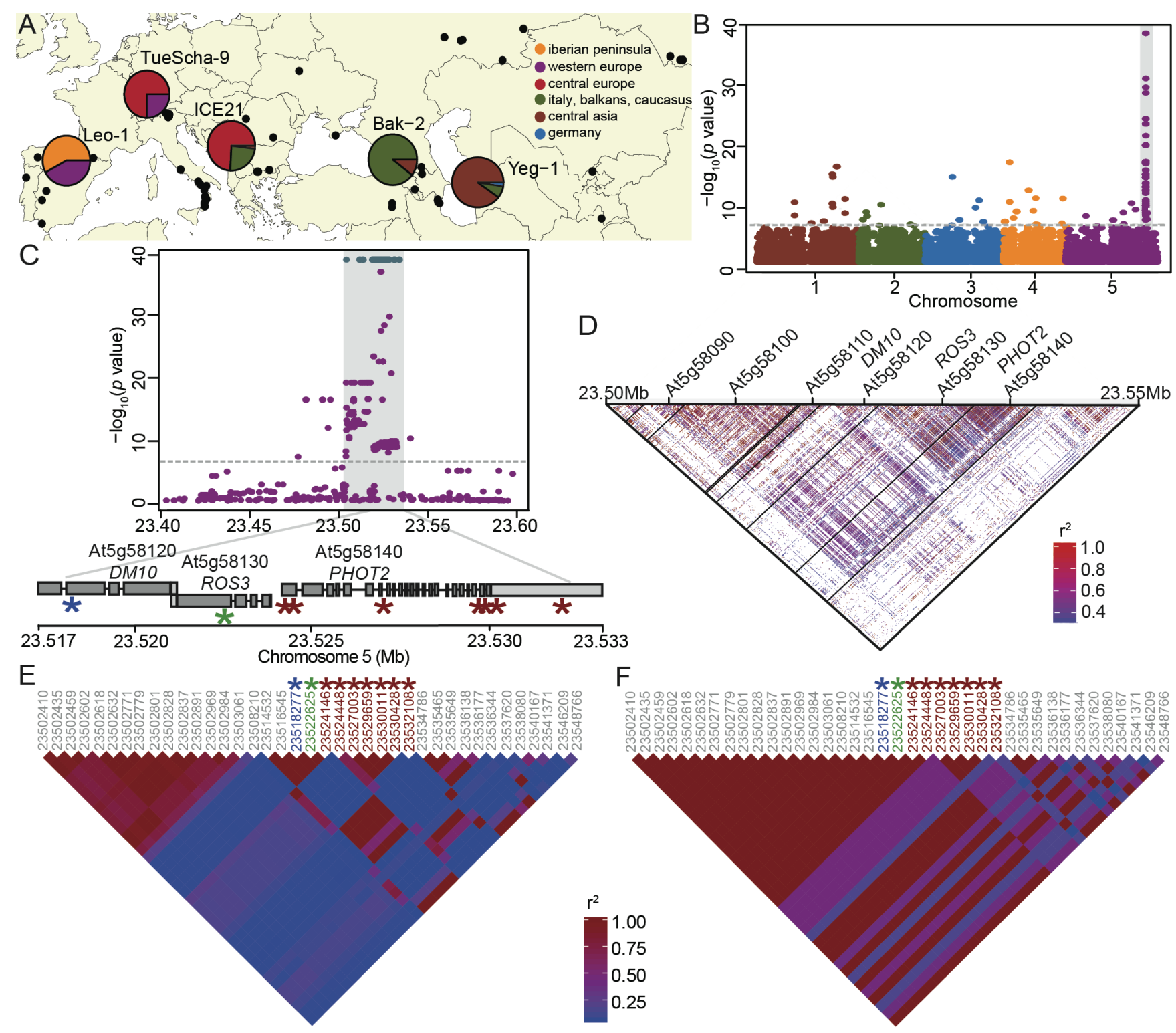

Fig 3. GWAS of hybrid necrosis in 80 accessions. A. Map of 80 accessions (black dots), with the five risk accessions colored according to I00I Genomes admixture groups (I00I Genomes Consortium 20I6). B. Manhattan plot for association of necrosis in Cdm-0 hybrid progeny when selfed and crossed to 79 other accessions. The significance threshold (Bonferroni correction, 5\% familywise error) is indicated as a horizontal dotted line (same in C). C. Close-up of the region highly associated with hybrid necrosis; SNPs with a I:I association marked in teal. Asterisks indicate such I:I associations in At5g58120, ROS3 and PHOT2; see also E and F. SNP positions are given in Table SI0. D. Linkage disequilibrium (LD) across a $50 \mathrm{~kb}$ region in chromosome 5. Strong linkage is observed from At5g58090 to At5g58।40. E. LD across the same $50 \mathrm{~kb}$ region as in $\mathrm{D}$, with a subset of markers from 80 accessions crossed to Cdm- 0 . Asterisks indicate markers highlighted in C. F. LD across a $50 \mathrm{~kb}$ region with the same markers as in $\mathrm{E}$, but for the five risk accessions only. Higher LD is seen here than in E. 


\section{Fine mapping of DMIO using Genome-Wide Association Studies}

In the original collection of 6,409 crosses among 80 accessions (Chae et al. 20I4), four accessions in addition to TueScha-9 produced severe hybrid necrosis when crossed to Cdm-0: Yeg-I, Bak-2, ICE2I and Leo-I. Together with TueScha-9, these represent much of the Eurasian range of the species, both geographically and genetically; six of the nine previously identified admixture groups (I00I Genomes Consortium 2016) are present in these five risk accessions (Fig 3A, Table S9). Given the diversity of the five incompatible accessions, and knowing that most, but not all, causal genes for hybrid incompatibility are NLRs, we attempted to narrow down causal DMIO candidate genes by GWAS, with Cdm-0-dependent $F_{1}$ necrosis as a binary trait (Grimm et al. 2016). We discovered a remarkably high association between this phenotype and several closely linked markers on the bottom of chromosome 5, with corrected $p$ values as low as 10-38. In addition, 79 SNPs showed a one-to-one association with the necrotic phenotype, resulting in - $\log _{10} p$ values of 0 (Fig 3B, Table S IO). The markers with the strongest associations tagged three loci: At5g58I20, encoding a TIR-NLR without known function, ROS3 (At5g58I30), encoding an enzyme involved in DNA demethylation (Zheng et al. 2008), and PHOT2 (At5g58I40), encoding a blue light receptor that mediates phototropism (Harada et al. 2003) (Fig 3C, Table S I0). These three loci are genetically similar among the five risk accessions, yet differentiated from the other 75 accessions used for GWAS (Fig S4A-C). Looking at linkage among loci in this genomic region, we could see that, when taking all 80 accessions into account, six loci (At5g58090-Atg58I40) belong to one large linkage block, in which ROS3 and PHOT2 are under tight linkage and the TIR-NLR At5g58I20 constitutes a separate linkage block (Fig 3D). Notably, in the five accessions causing hybrid incompatibility, stronger linkage is observed in this region than that seen among the same markers from all 80 accessions (Fig 3E, F). In the risk accessions, At5g58I20, ROS3 and the proximal part of PHOT2 form one linkage block, while SNPs located in the distal half of PHOT2 are found in a separate linkage block, rendering At5g58I20 and ROS3 as primary candidates for causality in hybrid necrosis (Fig 3F).

\section{DMIO, a singleton TIR-NLR, as cause of severe hybrid necrosis}

Having candidate genes for $D M / 0$, we next sought to experimentally test their causality for severe hybrid necrosis. Genomic fragments of the TIR-NLR At5g58I20 and ROS3, from both Col-0 and TueScha-9, were introduced into Cdm-0 plants. A $4.8 \mathrm{~kb}$ genomic fragment containing At5g58I20Tuescha-9 recapitulated the Cdm$0 \times$ TueScha-9 hybrid necrosis phenotype (Fig 4A, Table SII). At5g58I20 is henceforth called DMI0. When DM I O Tuescha-9 was introduced into a Col-0 background and the resulting $T_{\text {I }}$ plants were subsequently crossed to Cdm-0, we also observed the hybrid incompatibility phenotype in the $F_{1}$ progeny (Fig 4B). DM/OCol-0, ROS3TueScha-9 and ROS3Col-0 did not produce any necrosis when introduced into a Cdm-0 background (Table SII). We also observed that, when infiltrated in $\mathrm{N}$. benthamiana leaves and overexpressed under an EtOH- 
bioRxiv preprint doi: https://doi.org/10.1101/2020.05.18.101451; this version posted May 20, 2020. The copyright holder for this preprint (which was not certified by peer review) is the author/funder, who has granted bioRxiv a license to display the preprint in perpetuity. It is made available under aCC-BY 4.0 International license.

Barragan et al. Relocated singleton NLR and hybrid necrosis

inducible promoter, both $D M / 0^{C} \mathrm{Col}-0$ and DM I OTueScha-9 were able to trigger cell death, which was not the case when DMIOCol-0 and DM I OTueScha-9 were expressed under the control of their native promoters (Fig 4C). The cell death triggering activities under forced overexpression in the heterologous $N$. benthamiana system indicate that these NLRs are functional and competent in immune signaling.
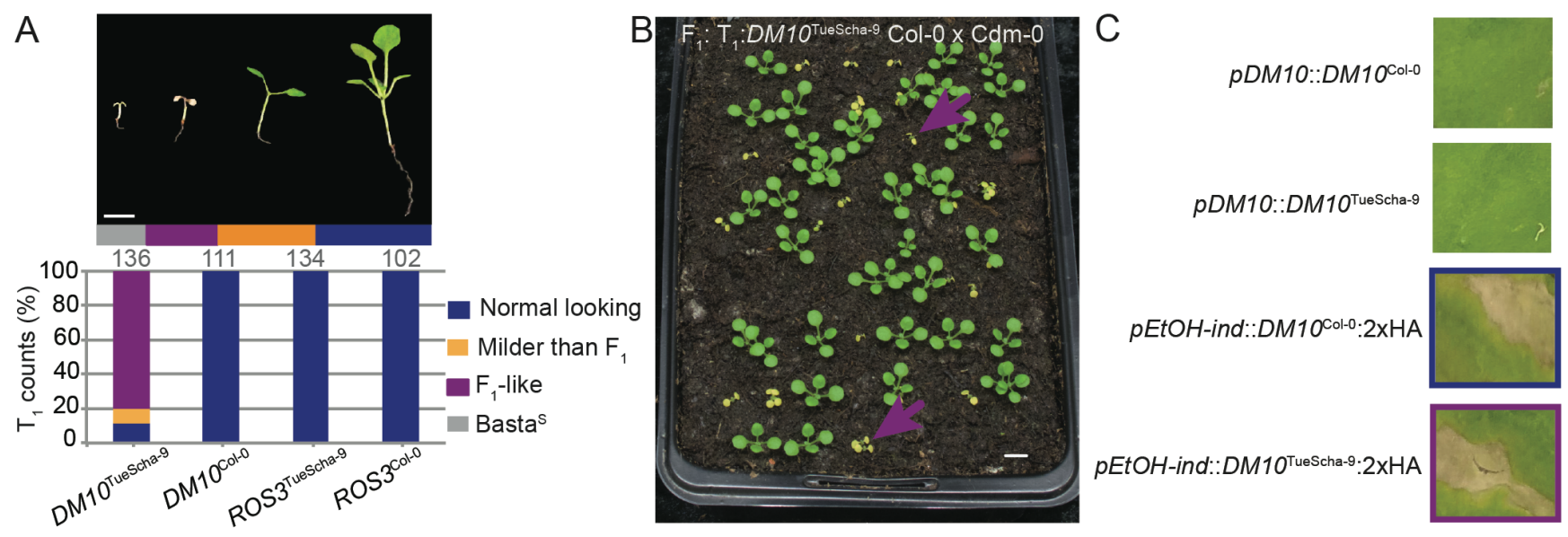

Fig 4. Experimental identification of DMIO. A. Recapitulation of hybrid necrosis in $25-d a y$ old $C d m-0$, plants transformed with the indicated genomic fragment from TueScha-9 or Col-0. Representative phenotype and total number of $T_{\text {I }}$ plants examined given on top. Plants were grown at $16^{\circ} \mathrm{C}$. Scale bar represents $1 \mathrm{~cm}$. B. The same $D M / 0^{\text {Tuescha- } 9}$ genomic fragment as in $A$ was introduced into Col-0, and $T_{1}$ plants were crossed to $\mathrm{Cdm}-0$. The $F_{1}$ hybrid phenotype was recapitulated (magenta arrows). Plants were 18 days old and grown at $16^{\circ} \mathrm{C}$. Scale bar represents $\mathrm{I} \mathrm{cm}$. C. Infiltration of $N$. benthamiana leaves with the indicated constructs. Overexpression of either DMIO TueScha-9 or $D M / 0^{\mathrm{Col}-0}$ under an EtOH inducible promoter ( $p E t O H$-ind) triggered cell death, while expression from their native promoter $(p D M / 0)$ did not.

\section{Prevalence and genetic differentiation of the DMIO risk allele in the global $A$. thaliana population}

To study natural variation across different DMIO alleles, 73 alleles belonging to accessions originating from across A. thaliana's native range were extracted from preliminary short- and long-read genome assemblies available in-house (Fig S5A, Table SI2). A Maximum-Likelihood (ML) tree showed that there are multiple well-supported DMIO clades (Fig S5B), and that variation between DMIO proteins was most prevalent at the C terminal end (Fig 5A, Fig S5C, Table SI3). Ten alleles were predicted to produce proteins truncated at three different points. Four accessions, including TueScha-9, the original DMIO risk allele carrier, share the same stop codon (Fig 5B, S5B), removing three LRRs. Five accessions had shorter, 335 amino acid long DMIO proteins; in these, the NBS domain was truncated, lacking motifs which are important regulators of NLR activity (Bendahmane et al. 2002; Sueldo et al. 2015; Bentham et al. 2017) (Fig 5B, Fig S5C). These five accessions carrying short DMIO alleles included Cdm- 0 and IP-Cum-I, which also carry DMII risk alleles. This implies that the short Cdm-0-like DMIO variants do not interact with DMII to produce hybrid necrosis. The shortest predicted DMIO protein, found in the Sha accession, was only 90 amino acids long and became 
truncated midway through the TIR-2 motif (Fig 5B, Fig S5C). The full-length DMIOCol-0 and the truncated DMIOTuescha-9 proteins differ only at $3 \%$ of shared sites, which is low for within-species variation among NLR alleles (Van de Weyer et al. 2019). As is typical for NLRs (Mondragón-Palomino et al. 2002; Ruggieri et al. 20I4), $\mathrm{Ka} / \mathrm{Ks}$ values above I were found in the LRR domain when comparing DMIOCol-0 and DMIOTuescha-9 (Fig 5C). In contrast, DMIOCol-0 and DMIOLerikI-3, which are both full-length DMIO proteins but from different clades, are more differentiated in TIR and NB-ARC domains, although $\mathrm{Ka} / \mathrm{Ks}$ values above $\mathrm{I}$ are also restricted to the LRR domain (Fig S5D).

Next, to assess how common the DMIO risk allele is in the global A. thaliana population, we again turned to the I00I Genomes collection (I00I Genomes Consortium 2016). Since DMIO, ROS3 and the proximal part of PHOT2 were strongly linked in accessions carrying the DMIO risk allele, we focused on this region, which contained 785 SNPs. In a NJ tree, all five confirmed DMIO risk allele carriers were found in the same branch, which included 95 other accessions (Fig 5D, Table SI4). In a PCA of this region, these 100 accessions were clearly separated from the rest (Fig 5E), which was not the case in a whole-genome PCA (Fig S5E), indicating that population structure is not the main driving force separating risk from non-risk allele carriers. To experimentally confirm that sequence was predictive of interaction with the DMII risk allele, 25 of the 100 accessions were crossed to Cdm-0 (Fig S5B, Table SI4). All but IP-Alm-0 produced hybrid necrosis.

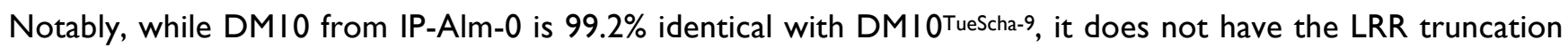
(Fig S5B). This implies that the truncation in DMIO risk alleles is likely responsible for incompatibility, and not individual amino acid changes. Ten random accessions not predicted to carry the DMIO risk allele were crossed to $\mathrm{Cdm}-\mathrm{O}$ as a control; as expected, none produced hybrid necrosis (Table SI4). Similarly, we investigated how common the other two DMIO truncations are in the global $A$. thaliana population. The shortest Sha-like DMIO allele was found in 29 accessions, while the Cdm-0-like truncation was more common, although not as common as the DMIO risk allele, and was found in 67 accessions (Table SI4).

In a $200 \mathrm{~kb}$ region around $D M / 0$, nucleotide diversity $(\pi)$ was highest, up to 0.015 , in the distal half of $D M / 0$, encoding the more polymorphic LRR domain (Fig 5F). However, in comparison with other TIR-NLRs present in most or all accessions, overall DMIO nucleotide diversity was not uncommon (Van de Weyer et al. 2019). Values for Tajima's $D$ reached 4.8 in the proximal half of $D M / 0$, hinting at multiple $D M / O$ alleles being prevalent at intermediate frequencies in the global A. thaliana population, as is often the case for NLRs (Caicedo et al. 1999; Stahl et al. 1999; Bakker et al. 2006; Karasov et al. 2014). Lastly, the fixation index ( $\left.F_{S T}\right)$ between 98 accessions with predicted DMIO risk alleles (excluding IP-Alm-0 and RAD-2I, which did not have truncated LRR domains) and I,037 non-risk allele carrying accessions, peaked at 0.88 across the DM I 0 linkage block (Fig 3D-F, Fig 5F). This was the only peak detected both across the entire chromosome 5 (Fig S5F) and the 
bioRxiv preprint doi: https://doi.org/10.1101/2020.05.18.101451; this version posted May 20, 2020. The copyright holder for this preprint (which was not certified by peer review) is the author/funder, who has granted bioRxiv a license to display the preprint in perpetuity. It is made available under aCC-BY 4.0 International license.

Barragan et al.

Relocated singleton NLR and hybrid necrosis

whole genome. Inside this block, a drop in $F_{S T}$ is seen over the proximal half of DMIO, which is consistent with this region being similar between risk and some non-risk alleles (Fig $\mathbf{5 C}$ ).

Taken together, these results show that there are multiple DMIO alleles in the global $A$. thaliana population, three of which are predicted to result in truncated proteins due to the presence of premature stop codons, one of which is the DMIO risk allele. Notably, the DMIO risk allele is not only relatively common and genetically differentiated in our GWAS population, but also in the global A. thaliana population.

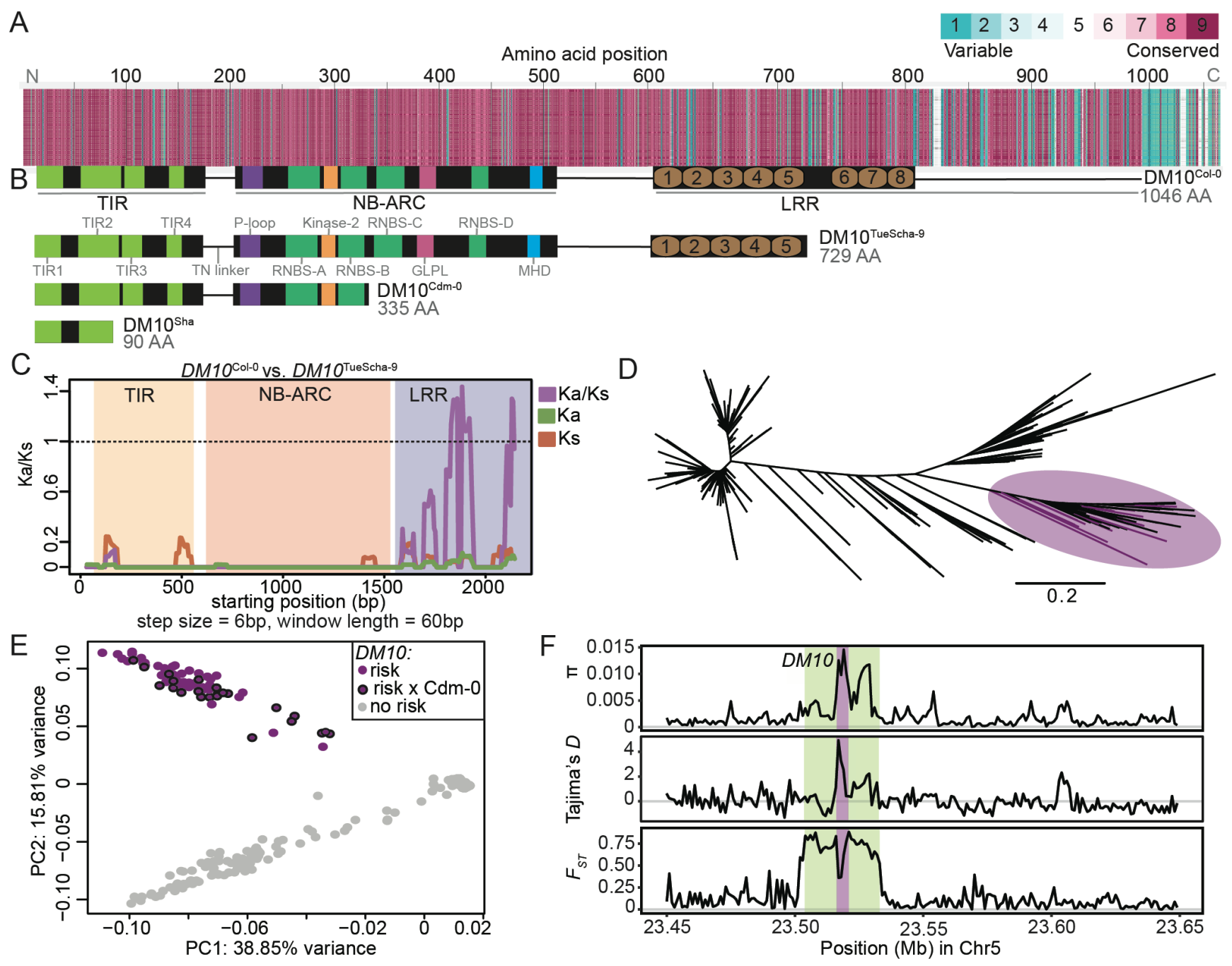

Fig 5. DMIO natural variation. A. Amino acid alignment of 73 DMIO proteins color-coded by its conservation score (Armon et al. 200I). B. Comparison between different DMI0 proteins (aligned with A). C. Ka/Ks ratios between DM I $0^{\text {Col-o }}$ and DM I $0^{\text {Tuescha-9. }}$. D. NJ tree of a region including DMIO, ROS3 and PHOT2 sequences from the 1001 Genomes Project (100I Genomes Consortium 2016). Branch lengths in nucleotide substitutions are indicated. Accessions carrying the DMIO risk alleles group together in a branch (magenta), risk accessions crossed to Cdm-0 are highlighted. E. PCA. Accessions carrying the predicted DMIO risk (magenta) versus non-risk (grey) alleles are clearly separated in PC2. Risk accessions crossed to Cdm-0 are outlined in black. F. $\pi$, Tajima's D and $F_{S T}$ for DMIO (magenta), the DM 10 linkage block comprising At5g58090-Atg58I40 (green) and surrounding genomic regions. 


\section{No documented co-occurrence of DMIO and DMII risk alleles in the global $A$. thaliana population}

Looking at the geographical distribution of accessions carrying different $D M / O$ alleles with premature stop codons, we observed that both the Cdm-0-like DMIO allele as well as the risk DMIO allele were found at similar densities throughout $A$. thaliana's native range, while the Sha-like DMIO allele was mainly found towards the eastern part of the species' distribution (Fig 6A, Table S I4). In the case of the DMIO risk allele, the one exception to where this allele was found, was the southwestern part of Spain and Portugal, even though $A$. thaliana has been heavily sampled in this region (I00I Genomes Consortium 2016). The fact that the only two DM I I risk carriers identified so far, Cdm-0 and IP-Cum-I, are found in southwestern Spain may indicate that the $D M I O$ and DMI I risk alleles do not geographically co-occur (Fig 6B).

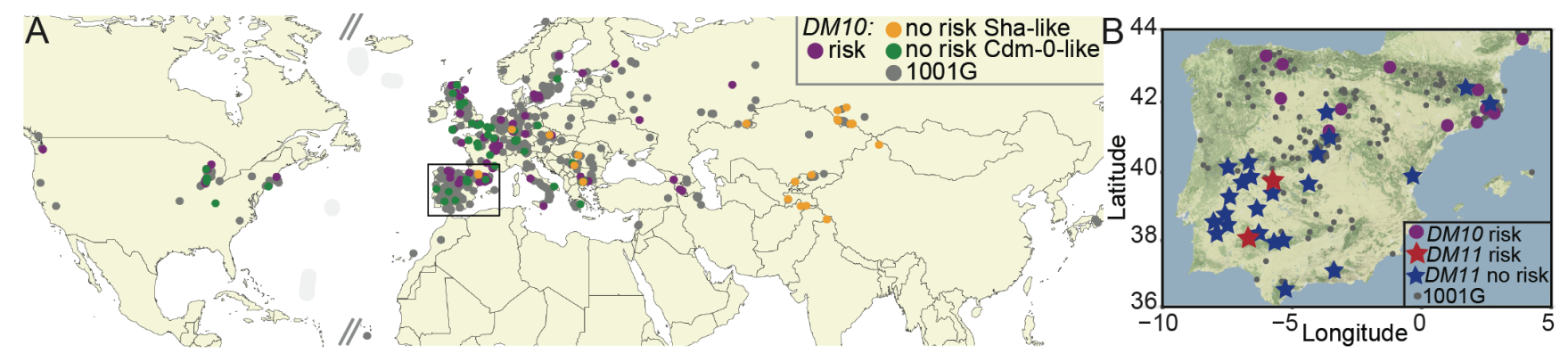

Fig 6. Geographical distribution of DMIO and DM I I alleles. A. Geographical distribution of I00I Genomes Project accessions (I00I Genomes Consortium 2016) carrying the DMIO risk (magenta), non-risk (grey) alleles, Sha-like non-risk (orange) and Cdm-0-like non-risk (green) alleles. Rectangle zooms into the region shown in B. B. Distribution of I00I Genomes Project accessions (grey) in Spain and Portugal, carrying the DMIO (magenta) and DMII (red) risk alleles, as well as accessions carrying DMI I non-risk alleles (blue) which were crossed to TueScha-9.

To provide additional support for this assertion, we first attempted to identify more DMII risk carriers in Spain and Portugal. We crossed TueScha-9, a DMIO risk allele carrier, to 24 accessions from these two countries, which were found at different geographical distances from the two DMII risk carriers Cdm-0 and IP-Cum-I, as well as from accessions carrying the DMIO risk allele (Table S7). No hybrid necrosis was observed in any of the resulting $F_{1}$ progeny (Fig 6B, Table S7). This, together with our aforementioned attempts to find additional DMII carriers among accessions that are closely related in the DMII genomic region to $\mathrm{Cdm}-0$ and IP-Cum-I, indicates that the $D M I I$ risk allele is rare and potentially only found in southwestern Spain, a region where the DMIO risk allele appears to be absent. 
bioRxiv preprint doi: https://doi.org/10.1101/2020.05.18.101451; this version posted May 20, 2020. The copyright holder for this preprint (which was not certified by peer review) is the author/funder, who has granted bioRxiv a license to display the preprint in perpetuity. It is made available under aCC-BY 4.0 International license.

Barragan et al.

Relocated singleton NLR and hybrid necrosis

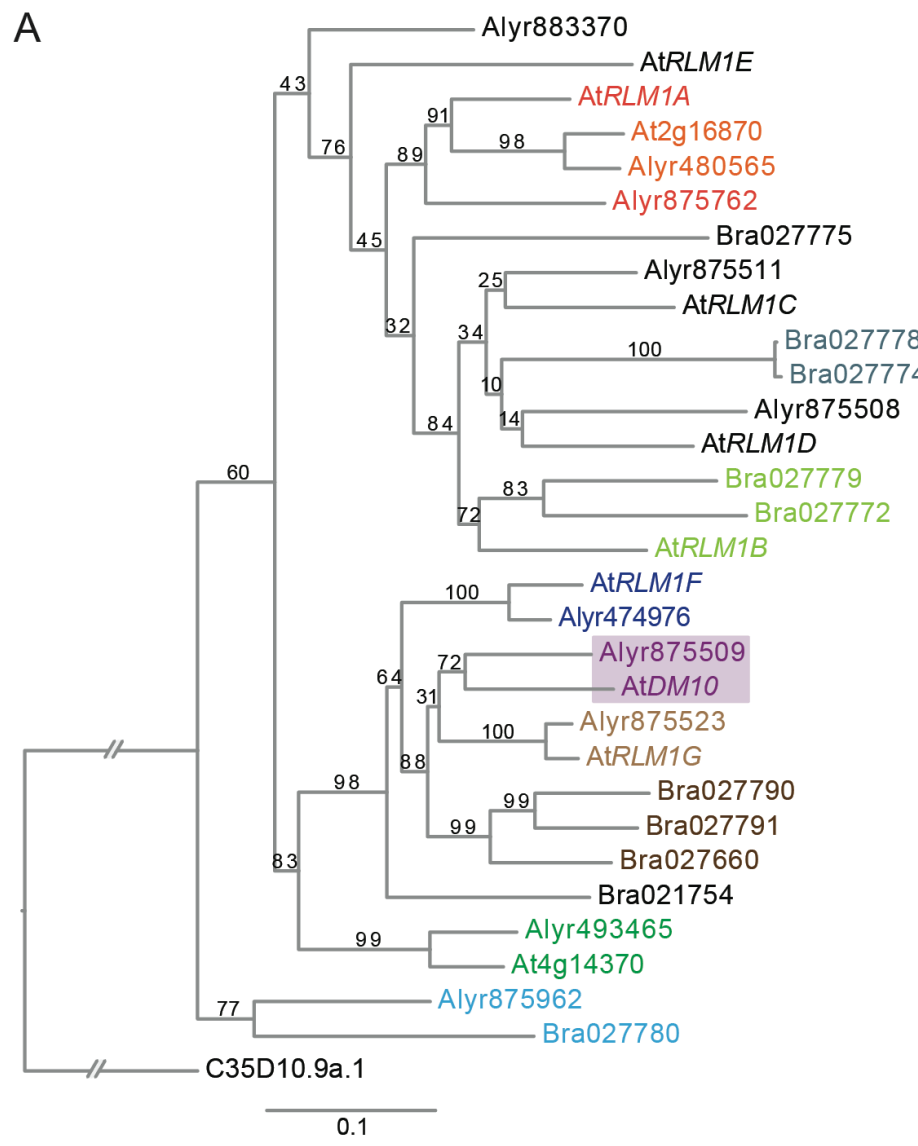

B $\quad$ B. rapa

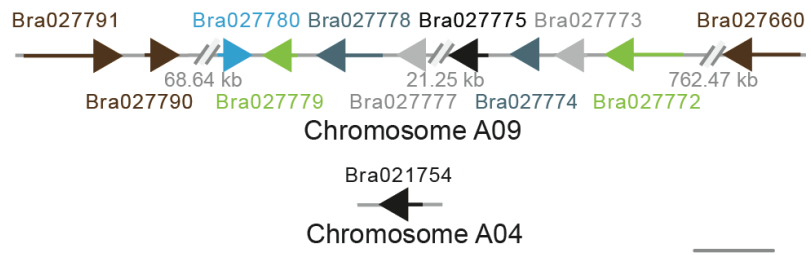

A. lyrata
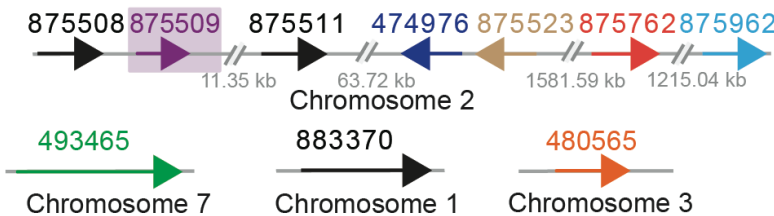

Chromosome $7 \quad$ Chromosome $1 \quad$ Chromosome 3

$4 \mathrm{~kb}$

A. thaliana
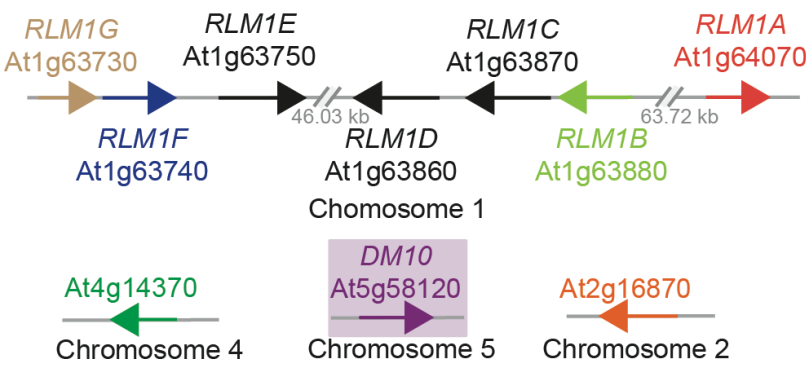

C

B. rapa
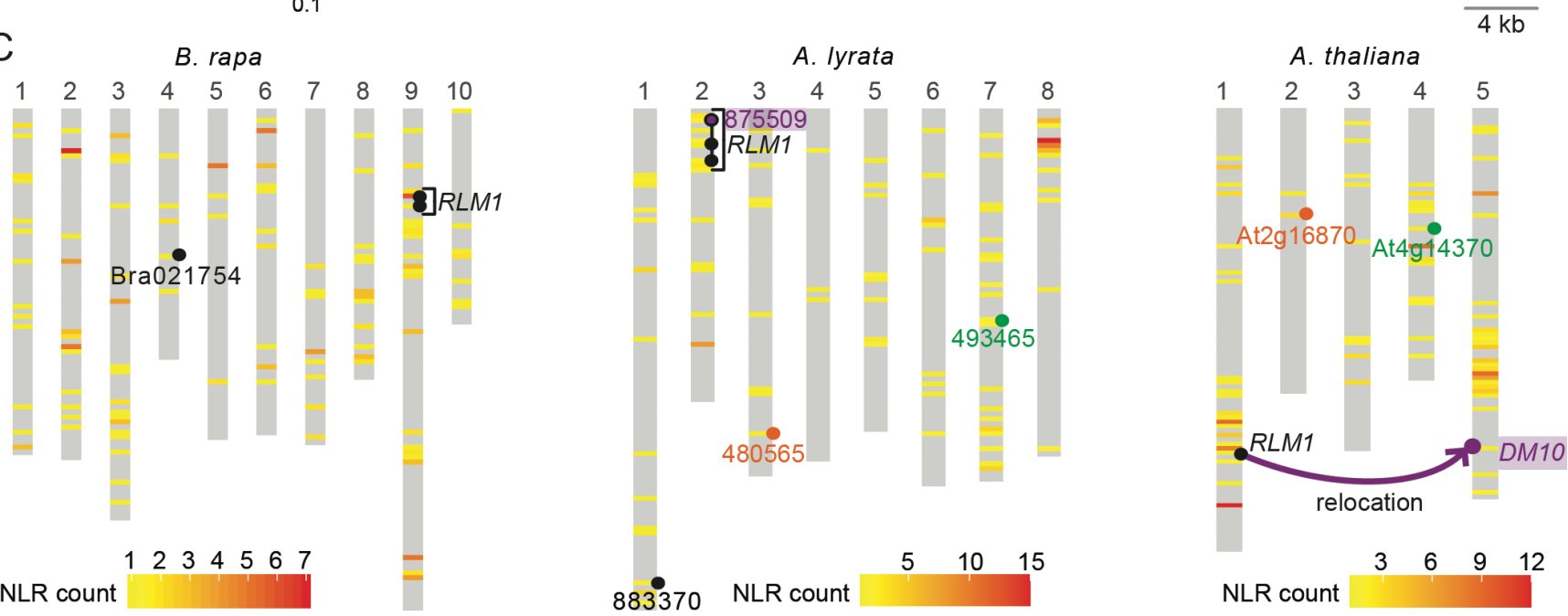

Fig 7. RLM I locus in B. rapa, A. lyrata and A. thaliana reference genomes. A. ML tree of the NBS domain (CDS) of RLMI cluster members from B. rapa, A. lyrata and A. thaliana, with the NBS domain of C. elegans CED-4 as outgroup (C35DI0.9a.I). I,000 bootstrap replicates were performed, values are shown on each branch. Branch lengths in nucleotide substitutions are indicated. The same color was chosen for genes in neighboring branches with bootstrapping values above 70. Diagonal lines indicate a gap in the tree branches. B. RLMI cluster members in B. rapa, $A$. lyrata and $A$. thaliana. Color-coding the same as in A, genes in grey are truncated, arrows represent size of NLR loci. Diagonal lines indicate a positional gap along the chromosome, the length of the gap is indicated. C. Heatmaps of NLR densities across the three genomes. Window sizes were calculated by dividing the length of the longest chromosome by 100 . RLMI cluster and closely related singletons indicated. DM 0 in A. thaliana and its homolog in A. lyrata, 875509 are highlighted in magenta. 


\section{Origin of the DMIO NLR singleton locus through a recent interchromosomal relocation event out of the RLMI cluster}

In the A. thaliana Col-0 reference genome, we identified nine NLR genes closely related to DMI0. Seven of these make up the RLMI cluster on chromosome I, and two others, At2gl6870, At4gl4370 are dispersed singletons. In the related species Arabidopsis lyrata and Brassica rapa, we identified a further 20 DMIO/RLMI homologs (Fig 7A). As in A. thaliana, the RLMI cluster in these two species underwent within-species duplication and inversion events (Fig 7B). Most RLMI members from A. thaliana have a clear one-to-one homolog in A. lyrata, so the expansion of the RLMI cluster must have occurred before the two species diverged (Beilstein et al. 2010). The A. lyrata homologs of At2gl6870 and At4g|4370, 480565 and 493465, are found in a different chromosome than the main RLMI cluster (Fig 7C). This is not the case for the DMIO homolog from A. lyrata, 875509, which is located inside the main RLMI cluster (Fig 7C). This indicates that DMIO was relocated away from the main RLMI cluster to another chromosome and that this occurred after $A$. lyrata and A. thaliana diverged.

\section{Discussion}

Over ten causal genes for hybrid necrosis have been identified in A. thaliana and other plants (Krüger et al. 2002; Bomblies et al. 2007; Alcázar et al. 2009; Jeuken et al. 2009; Yamamoto et al. 2010; Chae et al. 20l4; Chen et al. 2014; Todesco et al. 2014; Sicard et al. 2015; Deng et al. 2019). In many instances, at least one of the two causal genes is an NLR, which is also the case for the Cdm-0 0 TueScha- 9 incompatibility. What makes this case particularly interesting is the extreme severity of hybrid necrosis, the transcriptional hyper-induction of NLR genes, and the causality of a truncated singleton NLR, DMIO, which was recently relocated from a larger NLR cluster.

As with normal immune responses and autoimmune syndromes, the expression of hybrid necrosis is typically temperature-dependent, and hybrid necrosis in $A$. thaliana can usually be completely suppressed when grown above $23^{\circ} \mathrm{C}$ (Bomblies et al. 2007; Alcázar et al. 2009; Chae et al. 2014; Todesco et al. 20l4; Świadek et al. 2017). In contrast, Cdm-0 x TueScha-9 $F_{1}$ seedlings die even at $28^{\circ} \mathrm{C}$ (Chae et al. 20l4). In other necrotic hybrids, non-causal NLRs have been reported to be differentially expressed between hybrids and their parents (Bomblies et al. 2007), but not anywhere near the massive NLR induction seen in Cdm-0 x TueScha-9. In the $F_{1}$ progeny, 128 of 150 expressed NLRs are differentially expressed in at least one genotype comparison, with almost all being overexpressed. Simultaneous upregulation of several NLR genes has been observed after exposure to biotic (Zipfel et al. 2004; Tan et al. 2007; Ribot et al. 2008; Mohr et al. 2010; Yu et al. 20I3; Sohn et al. 2014; Chen et al. 20I5; Mine et al. 2018) and abiotic stresses (MacQueen and Bergelson 2016), but also 
not to the extent seen in Cdm-0 x TueScha-9 hybrids. Given that elevated NLR expression levels can trigger cell death (Stokes et al. 2002; Mackey et al. 2003; Palma et al. 2010; Lai and Eulgem 2018), we expect that NLR hyper-induction is a significant contributor to the strongly necrotic phenotype of Cdm-0 0 TueScha-9 $F_{\text {I }}$ hybrids.

NLR transcript levels are tightly controlled through a variety of regulatory mechanisms (Lai and Eulgem 2018), and large-scale upregulation of NLRs could possibly require multiple pathways. We found WRKY transcription factors to be overexpressed in the hybrid; these proteins bind to $W$ box motifs enriched in the promoters of multiple members of the plant immune system, including NLRs, and can induce widespread NLR expression, enhancing basal immunity (Eulgem and Somssich 2007; Pandey and Somssich 2009; Mohr et al. 2010). Two other mechanisms known to affect a broad set of NLRs is the miRNA-dependent phasiRNA production (Zhai et al. 20II; Li et al. 2012; Shivaprasad et al. 20I2; Xia et al. 20I5) as well as nonsense-mediated decay (NMD) (Gloggnitzer et al. 2014), both of which help to dampen NLR gene expression in the absence of pathogen threats. Repression is attenuated after an incoming pathogen is detected by the plant, enabling global NLR levels to increase (Lai and Eulgem 2018). While we have no direct evidence for transcription factors, small RNAs or NMD as contributors to aberrant NLR expression in the Cdm-0 0 TueScha-9 hybrid, this exceptional hybrid necrosis case may present a good tool for comparing NLR regulation under pathogen attack with strong autoimmunity.

Allelic variation in singleton NLRs can manifest itself as presence/absence polymorphisms, intragenic recombination events or single nucleotide changes (Caicedo et al. 1999; Stahl et al. 1999; Mauricio et al. 2003; Allen et al. 2004). Truncations may result, for example, from point mutations (Cao et al. 20II; Guo et al. 20II), alternative splicing or transcriptional termination (Costanzo and Jia 2009; Kim et al. 2009; Tsuchiya and Eulgem 2013). We found $17 \%$ of DMIO proteins encoded in a global set of $A$. thaliana accessions to be truncated in either their TIR, NBS or LRR domain. Similar to several full-length variants, the alleles for all three truncated proteins have intermediate frequencies and are relatively wide-spread, suggesting they are actively maintained in the global population by balancing selection. The most common of the three truncation alleles is the DMIO risk version, which has evidence for its LRR domain being under diversifying selection. While the TIR domain alone can induce cell death (Swiderski et al. 2009; Bernoux et al. 20II), a complete NBS domain is essential in many instances (Dinesh-Kumar et al. 2000; Dodds et al. 200I; Bendahmane et al. 2002; Tameling et al. 2002; Williams et al. 20II; Steinbrenner et al. 20I5; Sueldo et al. 20I5; Wang et al. 20I5; Bernoux et al. 2016). Thus, it is unclear whether the shorter DMIOCdm-0 or DMIOSha proteins are functional, even though their prevalence and geographical distribution suggest so. 
Because NLR allelic diversity is often not easily captured by short-read based resequencing (Van de Weyer et al. 2019), we still do not have a good grasp on whether NLR alleles in general, and specifically beneficial alleles, spread through the population more quickly than other adaptive alleles. The lberian peninsula is a center of $A$. thaliana genetic diversity, with strong geographical structure across a north-south latitudinal gradient (Picó et al. 2008; Brennan et al. 20I4). We observed a lack of co-occurrence between DMII risk alleles, restricted to southwestern Spain, and DMIO risk alleles, restricted to the northern half of Spain (I00I Genomes Consortium 2016). Absence of co-occurrence between risk alleles may partly be the result of population structure: two geographical barriers potentially reducing gene flow, the Tagus river and the Central System mountains, divide populations carrying either DMIO or DMII risk alleles. In any case, more definitive proof of the mutual exclusion of $D M I O$ and $D M I I$ risk alleles will require more extensive sampling of natural populations across the Iberian peninsula. Co-occurrence of hybrid incompatibility alleles in a single population has been observed before, where different alleles are maintained at intermediate frequencies, but in this case, the hybrids show a milder necrosis phenotype in the lab than $\mathrm{Cdm}-0 \times$ TueScha- 9 , and no obvious phenotype in the wild (Todesco et al. 2014). The extreme necrotic phenotype caused by the DMIO-DMII interaction, which appears to be largely independent of growth conditions, makes it unlikely that the hybrid phenotype would be suppressed in the wild. In addition, since outcrossing rates of $A$. thaliana in the wild can be substantial (Bomblies et al. 2010), it is conceivable that in some areas these rates are high enough for lethal hybrids to exact a noticeable fitness cost on risk allele carriers.

An interchromosomal relocalization event of the RLMI cluster gave rise to DMIO after $A$. thaliana speciation. Which evolutionary forces might have caused DMIO to be relocated to a separate chromosome, if any? NLR genes in clusters are likely to be more mutable than singletons because of illegitimate recombination (Michelmore and Meyers 1998; Baumgarten et al. 2003; Meyers et al. 2005; Wong and Wolfe 2005; Wicker et al. 2007). If $D M / O$ underwent beneficial neofunctionalization after duplication, its relocation away from the cluster might have stabilized the locus. Another possibility could be conflicts among gene cluster members. Cluster members are sometimes transcriptionally co-regulated (Yi and Richards 2007; Deng et al. 2017), so translocation away from the cluster would allow for evolution of new expression patterns for DM/0. More generally, genomic relocation would enable DMIO to be subjected to different selection regimes than its cluster homologs. Either way, the fact that the genomic region surrounding DMIO - different from some other RLMI cluster members - is a recombination cold spot (Choi et al. 2016) is consistent with our finding of high LD around the DMIO locus, especially in accessions carrying the DMIO risk allele. Together with our phylogenetic results and Tajima's $D$ measurements, this would seem to support the idea of stable DMIO haplotypes being particularly advantageous. 
In conclusion, we have presented a severe case of hybrid necrosis in $A$. thaliana, where the hybrid showed global NLR hyper-induction triggered by the interaction of $D M / 0$, a relocated singleton NLR, and $D M I I$, an unliked locus in chromosome I. It is noteworthy that the DMIO risk alleles lack a substantial portion of the coding region, including sequences for three of the eight LRRs found in the full-length variants. NLRs lacking the NBS or LRR domain are not only known to retain the ability to cause cell death, but there are cases where truncated NLRs are bona fide resistance genes (Nishimura et al. 2017; Roth et al. 2017; Marchal et al. 2018). Conversely, other proteins, including at least one full-length NLR, can induce cell death through activation of naturally occurring truncated NLRs (Zhao et al. 20I5; Zhang et al. 2017). In the case of DMI0, we do not know whether only the full-length variants or the truncated variants, or both, confer resistance to unknown pathogens. To answer this question, a new program is needed that systematically assigns function to all NLR alleles and genes in a species. Regardless of whether the truncated DMIO alleles have such activity, already with our current knowledge, the DMIOIDMII case provides a good tool to investigate the consequences of simultaneous activation of a large fraction of NLRs. In the future, by identifying the role of different alleles of DMIO and its homologs in the RLMI cluster in responses to natural pathogens, one could test whether chromosomal relocation affects how evolution is acting on this group of highly related NLR genes.

\section{Materials and Methods}

Constructs are listed in Table SI 5 and primers in Table SI6.

Sequencing data can be found at the European Nucleotide Archive (ENA) under accession number PRJEB38267 (RNA-seq experiment) and \#\# (Cdm-0 assembly) and in the GenBank under accession number \#\# (DMIO region).

\section{Plant material}

Stock numbers of accessions used are listed in Supplementary Material. All plants were stratified in the dark at $4^{\circ} \mathrm{C}$ for 4-6 days prior to planting on soil. Late flowering accessions were vernalized six weeks under short day conditions ( $8 \mathrm{~h} \mathrm{light)}$ at $4^{\circ} \mathrm{C}$. All plants were grown in long days $\left(16 \mathrm{~h}\right.$ of light) at $16^{\circ} \mathrm{C}$ or $23^{\circ} \mathrm{C}$ at $65 \%$ relative humidity under 110 to $140 \mu \mathrm{mol} \mathrm{m} \mathrm{m}^{-2} \mathrm{~s}^{-1}$ light provided by Philips GreenPower TLED modules (Philips Lighting GmbH, Hamburg, Germany).

\section{RNA sequencing}

Six biological replicates of 10 day-old shoots of Cdm- 0 × TueScha- 9 hybrids and their parental accessions were collected. RNA was extracted as described in (Yaffe et al. 2012). The NEBNext magnetic isolation module 
(New England Biolabs), was used for mRNA enrichment. Sequencing libraries were prepared using NEBNext Ultra II directional RNA library kit and paired-end sequenced (I50bp) in an Illumina HiSeq3000 (Illumina Inc., San Diego, USA) instrument. Reads were mapped against the A. thaliana reference TAIRI0 using bowtie2 (v.2.2.6) (Langmead and Salzberg 20I2). Default parameters were chosen unless mentioned otherwise. Transcript abundance was calculated with RSEM (v.I.2.3I) (Li and Dewey 20II). In silico hybrids were generated to enable mid-parent value calculations: parental read files were normalized according to sequencing depth and were subsampled by randomly drawing $50 \%$ of the reads with seqtk (v.2.0-r82-dirty; https://github.com/lh3/seqtk). Differential gene expression analyses were performed using DESeq2 (v.l.I8.I) (Love et al. 2014). Genes with less than ten counts over all 18 samples were removed from downstream analyses. Significant changes in gene expression between two genotypes were determined by filtering for genes with a $\mid \log _{2}$ FoldChange $\mid>I$ and padj value $<0.0$ I. One read was added to all normalized read counts in Fig IG and S2E to avoid plotting -INF values in non-expressed genes $\left(\log _{10}(0+1)=0\right)$. Non-additive gene expression between Cdm-0 x TueScha-9 $\mathrm{F}_{1}$ hybrids in silico hybrids was analyzed by computing principal components based on the normalized read counts of the top 500 most variable genes across all 18 samples. Plots were generated using the R package ggplot2 (v.3.2.0) (Wickham 2009) and heatmaps were plotted using pheatmap (v.l.0.8) (Kolde 20I2). Gene Ontology (GO) analyses were performed using AgriGO (Tian et al. 20I7) using the SEA method. The GO results were visualized with REVIGO treemap (Supek et al. 20II), for clearer visualization only the top 13 GO categories with the lowest $-\log _{10}(p$ value) were plotted, the complete list of GO terms is found in Table S2.

\section{Genotyping-by-sequencing and QTL mapping}

$F_{I}$ progeny from bi-directional crosses of $F_{I}($ TueScha-9/Col-0) $\times(\mathrm{Cdm}-0 / \mathrm{Col}-0)$ was used as a mapping population. The seedlings showing the hybrid necrosis phenotype vs. those that did not, were genotyped individually in a 1:I ratio. Plants were 10 days old when collected. Genomic DNA was extracted with CTAB (cetyl trimethyl ammonium bromide) buffer (Doyle and Doyle 1987) and then purified through chloroform extraction and isopropanol precipitation (Ashktorab and Cohen 1992). Genotyping-by-Sequencing (GBS) using RAD-seq was used to genotype individuals in the mapping populations with Kpnl tags (Rowan et al. 2017). Briefly, libraries were single-end sequenced on a HiSeq 3000 instrument with 150 bp reads. Reads were processed with Stacks (vl.35) (Catchen et al. 20I3) and mapped to TAIRIO with bwa-mem (v0.7.I5) (Li 20I3), variant calling was performed with GATK (v3.5) (McKenna et al. 2010). QTL was performed using R/qtl (Broman et al. 2003) with the information from $348 F_{2}$ individuals from 4 independent lines of this segregating population and 6179 markers. 


\section{De novo genome assembly and annotation}

The Cdm-0 accession (ID 9943; CS764I0) was grown as described above. To reduce starch accumulation, 3week-old plants were put into darkness for $30 \mathrm{~h}$ before harvesting. Sixteen grams of flash frozen leaf tissue were ground in liquid nitrogen and nuclei isolation was performed according to (Workman et al. 20/8) with the following modifications for A. thaliana: eight independent reactions of two grams each were carried out, and the filtered cellular homogenate was centrifuged at 7,000 x g. High-molecular-weight DNA was recovered with the Nanobind Plant Nuclei Kit (Circulomics; SKU NB-900-80I-0I), and needle-sheared Ix (ThermoFisher UK Ltd HCA-4 I3-030Y GC Syringe Replacement Parts 26g , $5 \mathrm{Imm}$ ). A 35-kb template library was prepared with the SMRTbell@ Express Template Preparation Kit 2.0, and size-selected with the BluePippin system according to the manufacturer's instructions (P/N I0I-693-800-0I, Pacific Biosciences, California, USA). The final library was sequenced on a Pacific Biosciences Sequel instrument with Binding Kit 3.0. PacBio long-reads were assembled with Canu (vI.7I) (Koren et al. 20I7). The resulting contigs were first polished using the long-reads with the Arrow algorithm (v2.3.2; https://github.com/PacificBiosciences/GenomicConsensus), followed by a second polishing step with PCR-free short-reads using the Pilon algorithm (vI.22) (Walker et al. 20I4). Lastly, the resulting contigs were scaffolded based on TAIRIO assembly by REVEAL (v0.2.I) (Linthorst et al. 20I5). The previously generated $\mathrm{Cdm}-0$ transcriptome sequencing data were mapped against the scaffolded genome assembly using HISAT (v.2.0.5) (Kim et al. 20I5)). Subsequently, the mapping results were used as extrinsic RNA sequencing evidence when annotating the genome using AUGUSTUS (v3.2.3) (Stanke et al. 2006).

\section{Manual NLR annotation of the DMI I mapping interval}

The 20-25 Mb region of chromosome I was extracted from the Cdm-0 assembly. The assembly was used as a query against a subject FASTA file containing 167 NLR genes from the Col-0 reference accession using blastn (Altschul et al. 1990). Hits were binned in $20 \mathrm{~kb}$ intervals and the percentage identity between the queries and the subject was visualized across all bins. NLRs between Atlg56510 to Atlg64070 in Col-0 found in this interval were manually annotated based on the percentage identity plotted and on AUGUSTUS gene predictions (v2.5.5) (Stanke et al. 2006).

\section{GWAS}

Cdm-0-dependent hybrid necrosis in the $F_{1}$ progeny from crosses with 80 accessions (Chae et al. 2014) was scored as 0 or I. The binary trait with accession information was submitted to the easyGWAS platform (Grimm et al. 2016) using the FaSTLMM algorithm. A - $\log _{10}(p$ value) was calculated for every SNP along the five A. thaliana chromosomes. 


\section{Constructs and transgenic lines}

Genomic fragments were PCR amplified, cloned into PGEM®-T Easy (Promega, Madison, WI, USA) and then transferred to the binary vector pMLBart, pCambial300 or pFK210. Constructs were introduced into plants

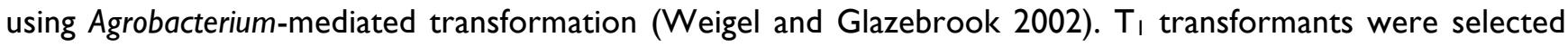
on BASTA (pMLBart and pFK210) and crossed to incompatible accessions. Ethanol-inducible constructs were PCR amplified, cloned into PGEM®-T Easy, as part of a separate experiment, 2xHA tags were added via PCR and the whole fragment, which was then transferred to the $\mathrm{PCR} 8 \AA$ entry vector (ThermoFisher Scientific). Next, the genomic fragment was moved to the destination vector pZZ006 (Caddick et al. 1998) through the Gateway ${ }^{\circledR}$ LR reaction (ThermoFisher Scientific). Quality control for all constructs was done by Sanger sequencing. For transient expression in N. benthamiana, A. tumefaciens were grown to an $\mathrm{OD}_{600}$ of I.2-I.8, incubated in induction medium ( $10 \mathrm{mM}$ MES ( $\mathrm{pH} 5.6), 10 \mathrm{mM} \mathrm{MgCl} 2$, and $150 \mu \mathrm{M}$ acetosyringone). The cell suspensions were normalized to an $\mathrm{OD}_{600}$ of 0.8 and co-infiltrations suspensions were mixed I:I. Suspensions were then infiltrated into the abaxial side of $\mathrm{N}$. benthamiana leaves. In the case of EtOH inducible constructs, infiltrated $N$. benthamiana were induced at $18 \mathrm{~h}$ post-infiltration (hpi) by irrigation with $1 \%$ ethanol and kept within a transparent plastic dome for another $18 \mathrm{~h}$. DMIO N. benthamiana constructs were co-expressed with a 35S::GFP construct as part of a larger experiment to test for candidate DM I I loci.

\section{Population genetic analyses}

Amino acid sequence conservation scores were calculated with ConSurf (Armon et al. 200I; Ashkenazy et al. 2016). SNPs occurring in repetitive regions and only present in one of the 73 extracted DMIO alleles were considered sequencing errors and were manually curated. Protein domains were predicted using InterProScan (Jones et al. 20I4). LRR domains were predicted with LRRsearch and the score threshold was set at 7 (Bej et al. 2014). NLR motifs were defined based on previous studies (Meyers et al. 2003; Shao et al. 2016). Nonsynonymous to synonymous substitution rates were calculated using KaKs_Calculator (v2.0) (Wang et al. 2010) with the NG method (Nei and Gojobori 1986); a window length of 60 bp and a step size of 6 bp were chosen. Genomic regions of interest were subsetted from a II35 genomes VCF file (I00I Genomes Consortium 2016) using VCFtools (v0.I.I4) (Danecek et al. 20II). The resulting VCF file was filtered by $M A F=0.01$ and a maximum percent of missing data per SNP of $30 \%$. Sequences were converted to FASTA, aligned with MUSCLE (v3.8.3I) (Edgar 2004) and then visualized with Aliview (vl.I8.I) (Larsson 20I4). Neighbor-Joining trees were calculated with Fastphylo (vl.0.I) (Khan et al. 20I3) and visualized with iTol (Letunic and Bork 2007). Maximum-likelihood trees were calculated with RaxML (v.0.6.0) using the GTR+G4 model (Stamatakis 20I4). Linkage disequilibrium ( $\left.r^{2}\right)$, was calculated with PLINK (v.l.90) (Purcell et al. 2007). Principal component analyses were calculated with smartPCA (Patterson et al. 2006). Tajima's D, $F_{S T}$, and 
nucleotide diversity (I) were also calculated with VCFtools. Maps were created with the R-packages maps (v3.3) and ggmap (v3.0) (Kahle and Wickham 2013). Admixture groups were assigned to each accession in accordance with the 100 I Genomes project (I00I Genomes Consortium 2016); since TueScha-9 had not been part of that study, admixture group assignments for it were estimated based on the genetic make-up of neighboring accessions. RLMI homologs in A. lyrata and B. rapa were identified using the Ensembl Plants portal (Bolser et al. 20I6). Sequences from the genome assemblies TAIRIO (A. thaliana), B. rapa ( $v I .5)$ and A. lyrata (vI.0) were used for phylogenetic analyses.

\section{Author contributions}

Conceptualization: $A C B, D W, E C$.

Formal analysis: $A C B, M C, R L, F R, H A, E C$.

Funding acquisition: DW, EC.

Investigation: $A C B, J W, W Y C$, EC.

Methodology: ACB, EC.

Project administration: DW.

Supervision: DW.

Writing - original draft: $A C B$.

Writing - review \& editing: $A C B, D W, E C$.

\section{Competing interests.}

The authors have declared that no competing interests exist.

\section{Funding}

This work was supported by the ERC Advanced Grant IMMUNEMESIS (340602), the Deutsche Forschungsgemeinschaft through the Collaborative Research Center ( $\mathrm{CRCIIOI}$ ), the Max Planck Society (to D.W.) and the Academic Research Fund (MOE2019-T2-I-134) from the Ministry of Education, Singapore, Intramural Research Fund (R-I54-000-B33-II4) from the National University of Singapore (to E.C.). The funders had no role in study design, data collection and analysis, decision to publish, or preparation of the manuscript. 
bioRxiv preprint doi: https://doi.org/10.1101/2020.05.18.101451; this version posted May 20, 2020. The copyright holder for this preprint (which was not certified by peer review) is the author/funder, who has granted bioRxiv a license to display the preprint in perpetuity. It is made available under aCC-BY 4.0 International license.

Barragan et al. Relocated singleton NLR and hybrid necrosis

\section{Acknowledgements}

We thank Sang-Tae Kim and members of the Weigel lab for critical reading of the manuscript, Christa Lanz for preparing the Cdm-O PacBio library, Lei Li for performing the RLMI N. benthamiana transient expressions, Rebecca Schwab for generating a few crosses as well as Gautam Shirsekar and Sergio Latorre for discussion. We also thank the $100 \mathrm{IG}+$ team for providing access to preliminary whole genome $A$. thaliana assemblies.

\section{References}

I00I Genomes Consortium. 2016. I,I35 Genomes Reveal the Global Pattern of Polymorphism in Arabidopsis thaliana. Cell I66:48I-49I.

Ade J, DeYoung BJ, Golstein C, Innes RW. 2007. Indirect activation of a plant nucleotide binding site-leucinerich repeat protein by a bacterial protease. PNAS 104:253I-2536.

Alcázar R, García AV, Parker JE, Reymond M. 2009. Incremental steps toward incompatibility revealed by Arabidopsis epistatic interactions modulating salicylic acid pathway activation. PNAS 106:334-339.

Allen RL, Bittner-Eddy PD, Grenville-Briggs LJ, Meitz JC, Rehmany AP, Rose LE, Beynon JL. 2004. Host-parasite coevolutionary conflict between Arabidopsis and downy mildew. Science 306:1957-1960.

Altschul SF, Gish W, Miller W, Myers EW, Lipman DJ. 1990. Basic local alignment search tool. J. Mol. Biol. 2I5:403-4I0.

Armon A, Graur D, Ben-Tal N. 200I. ConSurf: an algorithmic tool for the identification of functional regions in proteins by surface mapping of phylogenetic information. J. Mol. Biol. 307:447-463.

Ashkenazy H, Abadi S, Martz E, Chay O, Mayrose I, Pupko T, Ben-Tal N. 2016. ConSurf 2016: an improved methodology to estimate and visualize evolutionary conservation in macromolecules. Nucleic Acids Res. 44:W344-W350.

Ashktorab H, Cohen RJ. 1992. Facile isolation of genomic DNA from filamentous fungi. Biotechniques 13:198200.

Bakker EG, Toomajian C, Kreitman M, Bergelson J. 2006. A genome-wide survey of $R$ gene polymorphisms in Arabidopsis. Plant Cell 18:1803-1818.

Barragan CA, Wu R, Kim S-T, Xi W, Habring A, Hagmann J, Van de Weyer A-L, Zaidem M, Ho WWH, Wang G, et al. 2019. RPW8/HR repeats control NLR activation in Arabidopsis thaliana. PLoS Genet. I5:el0083I3.

Baumgarten A, Cannon S, Spangler R, May G. 2003. Genome-level evolution of resistance genes in Arabidopsis thaliana. Genetics 165:309-319.

Beilstein MA, Nagalingum NS, Clements MD, Manchester SR, Mathews S. 2010. Dated molecular phylogenies indicate a Miocene origin for Arabidopsis thaliana. PNAS 107:18724-18728.

Bej A, Sahoo BR, Swain B, Basu M, Jayasankar P, Samanta M. 2014. LRRsearch: An asynchronous server-based application for the prediction of leucine-rich repeat motifs and an integrative database of NOD-like receptors. Comput. Biol. Med. 53:164-I70.

Bendahmane A, Farnham G, Moffett P, Baulcombe DC. 2002. Constitutive gain-of-function mutants in a nucleotide binding site-leucine rich repeat protein encoded at the Rx locus of potato. Plant J. 32:195-204.

Bentham A, Burdett H, Anderson PA, Williams SJ, Kobe B. 2017. Animal NLRs provide structural insights into plant NLR function. Ann. Bot. I 19:827-702.

Bernoux M, Burdett H, Williams SJ, Zhang X, Chen C, Newell K, Lawrence GJ, Kobe B, Ellis JG, Anderson PA, et al. 2016. Comparative Analysis of the Flax Immune Receptors L6 and L7 Suggests an Equilibrium-Based Switch Activation Model. Plant Cell 28:146-159.

Bernoux M, Ve T, Williams S, Warren C, Hatters D, Valkov E, Zhang X, Ellis JG, Kobe B, Dodds PN. 201 I. 
bioRxiv preprint doi: https://doi.org/10.1101/2020.05.18.101451; this version posted May 20, 2020. The copyright holder for this preprint (which was not certified by peer review) is the author/funder, who has granted bioRxiv a license to display the preprint in perpetuity. It is made available under aCC-BY 4.0 International license.

Barragan et al. Relocated singleton NLR and hybrid necrosis

Structural and functional analysis of a plant resistance protein TIR domain reveals interfaces for selfassociation, signaling, and autoregulation. Cell Host Microbe 9:200-2II.

Bolser D, Staines DM, Pritchard E, Kersey P. 2016. Ensembl Plants: Integrating Tools for Visualizing, Mining, and Analyzing Plant Genomics Data. Methods Mol. Biol. I374:I I5-140.

Bomblies K, Lempe J, Epple P, Warthmann N, Lanz C, Dangl JL, Weigel D. 2007. Autoimmune response as a mechanism for a Dobzhansky-Muller-type incompatibility syndrome in plants. PLoS Biol. 5:e236.

Bomblies K, Yant L, Laitinen RA, Kim S-T, Hollister JD, Warthmann N, Fitz J, Weigel D. 20I0. Local-scale patterns of genetic variability, outcrossing, and spatial structure in natural stands of Arabidopsis thaliana. PLoS Genet. 6:el000890.

Botella MA, Parker JE, Frost LN, Bittner-Eddy PD, Beynon JL, Daniels MJ, Holub EB, Jones JD. 1998. Three genes of the Arabidopsis RPPI complex resistance locus recognize distinct Peronospora parasitica avirulence determinants. Plant Cell 10:1847-1860.

Brennan AC, Méndez-Vigo B, Haddioui A, Martínez-Zapater JM, Picó FX, Alonso-Blanco C. 20I4. The genetic structure of Arabidopsis thaliana in the south-western Mediterranean range reveals a shared history between North Africa and southern Europe. BMC Plant Biol. 14: 17.

Broman KW, Wu H, Sen S, Churchill GA. 2003. R/qtl: QTL mapping in experimental crosses. Bioinformatics 19:889-890.

Caddick MX, Greenland AJ, Jepson I, Krause KP, Qu N, Riddell KV, Salter MG, Schuch W, Sonnewald U, Tomsett $A B$. 1998. An ethanol inducible gene switch for plants used to manipulate carbon metabolism. Nat. Biotechnol. 16:177-180.

Caicedo AL, Schaal BA, Kunkel BN. 1999. Diversity and molecular evolution of the RPS2 resistance gene in Arabidopsis thaliana. PNAS 96:302-306.

Cao J, Schneeberger K, Ossowski S, Günther T, Bender S, Fitz J, Koenig D, Lanz C, Stegle O, Lippert C, et al. 201 I. Whole-genome sequencing of multiple Arabidopsis thaliana populations. Nat. Genet. 43:956-963.

Catchen J, Hohenlohe PA, Bassham S, Amores A, Cresko WA. 2013. Stacks: an analysis tool set for population genomics. Mol. Ecol. 22:3 I24-3I40.

Chae E, Bomblies K, Kim S-T, Karelina D, Zaidem M, Ossowski S, Martín-Pizarro C, Laitinen RAE, Rowan BA, Tenenboim $\mathrm{H}$, et al. 2014. Species-wide genetic incompatibility analysis identifies immune genes as hot spots of deleterious epistasis. Cell I59:I34I-I35I.

Chen C, Chen H, Lin Y-S, Shen J-B, Shan J-X, Qi P, Shi M, Zhu M-Z, Huang X-H, Feng Q, et al. 20I4. A twolocus interaction causes interspecific hybrid weakness in rice. Nat. Commun. 5:3357.

Chen J, Pang W, Chen B, Zhang C, Piao Z. 2015. Transcriptome Analysis of Brassica rapa Near-Isogenic Lines Carrying Clubroot-Resistant and -Susceptible Alleles in Response to Plasmodiophora brassicae during Early Infection. Front. Plant Sci. 6:1 I83.

Choi K, Reinhard C, Serra H, Ziolkowski PA, Underwood CJ, Zhao X, Hardcastle TJ, Yelina NE, Griffin C, Jackson M, et al. 2016. Recombination Rate Heterogeneity within Arabidopsis Disease Resistance Genes. PLoS Genet. 12:e1006179.

Conant GC, Wolfe KH. 2008. Turning a hobby into a job: how duplicated genes find new functions. Nat. Rev. Genet. 9:938-950.

Cooper JC, Guo P, Bladen J, Phadnis N. 2019. A triple-hybrid cross reveals a new hybrid incompatibility locus between D. melanogaster and D. sechellia. bioRxiv:590588.

Costanzo S, Jia Y. 2009. Alternatively spliced transcripts of Pi-ta blast resistance gene in Oryza sativa. Plant Sci. 177:468-478.

Danecek P, Auton A, Abecasis G, Albers CA, Banks E, DePristo MA, Handsaker RE, Lunter G, Marth GT, Sherry ST, et al. 20II. The variant call format and VCFtools. Bioinformatics 27:2I56-2I58.

Deng J, Fang L, Zhu X, Zhou B, Zhang T. 2019. A CC-NBS-LRR gene induces hybrid lethality in cotton. J. Exp. Bot. 70:5 I45-5I56.

Deng Y, Zhai K, Xie Z, Yang D, Zhu X, Liu J, Wang X, Qin P, Yang Y, Zhang G, et al. 2017. Epigenetic regulation of antagonistic receptors confers rice blast resistance with yield balance. Science 355:962-965.

Dinesh-Kumar SP, Tham WH, Baker BJ. 2000. Structure-function analysis of the tobacco mosaic virus resistance gene N. PNAS. 97:| 4789-I4794. 
bioRxiv preprint doi: https://doi.org/10.1101/2020.05.18.101451; this version posted May 20, 2020. The copyright holder for this preprint (which was not certified by peer review) is the author/funder, who has granted bioRxiv a license to display the preprint in perpetuity. It is made available under aCC-BY 4.0 International license.

Barragan et al. Relocated singleton NLR and hybrid necrosis

Ding P, Ngou BPM, Furzer OJ, Sakai T, Shrestha RK, MacLean D, Jones JDG. 2020. High-resolution expression profiling of selected gene sets during plant immune activation. Plant Biotechnol. J. I- 10

Dodds PN, Lawrence GJ, Ellis JG. 200I. Six amino acid changes confined to the leucine-rich repeat betastrand/beta-turn motif determine the difference between the $\mathrm{P}$ and $\mathrm{P} 2$ rust resistance specificities in flax. Plant Cell 13:163-178.

Dodds PN, Rathjen JP. 2010. Plant immunity: towards an integrated view of plant-pathogen interactions. Nat. Rev. Genet. II:539-548.

Doyle JJ, Doyle JL. 1987. A rapido DNA isolation procedure for small quantities of frech leaf tissue. Phytochemical Bulletin. 19 (I) II-I5.

Edgar RC. 2004. MUSCLE: multiple sequence alignment with high accuracy and high throughput. Nucleic Acids Res. 32:1792-1797.

Eulgem T, Somssich IE. 2007. Networks of WRKY transcription factors in defense signaling. Curr. Opin. Plant Biol. 10:366-37I.

Force A, Lynch M, Pickett FB, Amores A, Yan YL, Postlethwait J. 1999. Preservation of duplicate genes by complementary, degenerative mutations. Genetics I5 I:I53 I-1545.

Gloggnitzer J, Akimcheva S, Srinivasan A, Kusenda B, Riehs N, Stampfl H, Bautor J, Dekrout B, Jonak C, Jiménez-Gómez JM, et al. 20I4. Nonsense-mediated mRNA decay modulates immune receptor levels to regulate plant antibacterial defense. Cell Host Microbe 16:376-390.

Grimm DG, Roqueiro D, Salome P, Kleeberger S, Greshake B, Zhu W, Liu C, Lippert C, Stegle O, Schölkopf B, et al. 2016. easyGWAS: A Cloud-based Platform for Comparing the Results of Genome-wide Association Studies. Plant Cell 29 (I): 5-19

Guo Y-L, Fitz J, Schneeberger K, Ossowski S, Cao J, Weigel D. 20II. Genome-Wide Comparison of Nucleotide-Binding Site-Leucine-Rich Repeat-Encoding Genes in Arabidopsis. Plant Physiol. 157:757-769.

Harada A, Sakai T, Okada K. 2003. Photl and phot2 mediate blue light-induced transient increases in cytosolic $\mathrm{Ca}+$ differently in Arabidopsis leaves. PNAS 100:8583-8588.

Holub EB. 200I. The arms race is ancient history in Arabidopsis, the wildflower. Nat. Rev. Genet. 2:5I6-527.

Jacob F, Vernaldi S, Maekawa T. 20 I3. Evolution and Conservation of Plant NLR Functions. Front. Immunol. 4:297.

Jeuken MJW, Zhang NW, McHale LK, Pelgrom K, den Boer E, Lindhout P, Michelmore RW, Visser RGF, Niks RE. 2009. Rin4 causes hybrid necrosis and race-specific resistance in an interspecific lettuce hybrid. Plant Cell 21:3368-3378.

Jiao W-B, Schneeberger K. 2020. Chromosome-level assemblies of multiple Arabidopsis genomes reveal hotspots of rearrangements with altered evolutionary dynamics. Nat. Commun. 1 I:989.

Jones JDG, Dangl JL. 2006. The plant immune system. Nature 444:323-329.

Jones JDG, Vance RE, Dangl JL. 2016. Intracellular innate immune surveillance devices in plants and animals. Science 354(6395).

Jones P, Binns D, Chang H-Y, Fraser M, Li W, McAnulla C, McWilliam H, Maslen J, Mitchell A, Nuka G, et al. 2014. InterProScan 5: genome-scale protein function classification. Bioinformatics 30:1236-1240.

Kahle D, Wickham H. 20 I3. ggmap: Spatial Visualization with ggplot2. R J. 5:I44-16I.

Karasov TL, Kniskern JM, Gao L, DeYoung BJ, Ding J, Dubiella U, Lastra RO, Nallu S, Roux F, Innes RW, et al. 2014. The long-term maintenance of a resistance polymorphism through diffuse interactions. Nature 51 2:436-440.

Khan MA, Elias I, Sjölund E, Nylander K, Guimera RV, Schobesberger R, Schmitzberger P, Lagergren J, Arvestad L. 20I3. Fastphylo: fast tools for phylogenetics. BMC Bioinformatics I4:334.

Kim D, Langmead B, Salzberg SL. 20 I5. HISAT: a fast spliced aligner with low memory requirements. Nat. Methods 12:357-360.

Kim SH, Kwon SI, Saha D, Anyanwu NC, Gassmann W. 2009. Resistance to the Pseudomonas syringae effector HopAI is governed by the TIR-NBS-LRR protein RPS6 and is enhanced by mutations in SRFRI. Plant Physiol. I50:1723-1732.

Kim S, Park J, Yeom S-I, Kim Y-M, Seo E, Kim K-T, Kim M-S, Lee JM, Cheong K, Shin H-S, et al. 2017. New reference genome sequences of hot pepper reveal the massive evolution of plant disease-resistance genes 
bioRxiv preprint doi: https://doi.org/10.1101/2020.05.18.101451; this version posted May 20, 2020. The copyright holder for this preprint (which was not certified by peer review) is the author/funder, who has granted bioRxiv a license to display the preprint in perpetuity. It is made available under aCC-BY 4.0 International license.

Barragan et al. Relocated singleton NLR and hybrid necrosis

by retroduplication. Genome Biol. 18:210.

Klepikova AV, Kasianov AS, Gerasimov ES, Logacheva MD, Penin AA. 2016. A high resolution map of the Arabidopsis thaliana developmental transcriptome based on RNA-seq profiling. Plant J. 88:1058-1070.

Kolde R. 2012. Pheatmap: pretty heatmaps. R package version 61:617.

Koren S, Walenz BP, Berlin K, Miller JR, Bergman NH, Phillippy AM. 2017. Canu: scalable and accurate longread assembly via adaptive k-mer weighting and repeat separation. Genome Res. 27:722-736.

Krasileva KV, Dahlbeck D, Staskawicz BJ. 2010. Activation of an Arabidopsis resistance protein is specified by the in planta association of its leucine-rich repeat domain with the cognate oomycete effector. Plant Cell 22:2444-2458.

Krüger J, Thomas CM, Golstein C, Dixon MS, Smoker M, Tang S, Mulder L, Jones JDG. 2002. A tomato cysteine protease required for Cf-2-dependent disease resistance and suppression of autonecrosis. Science 296:744-747.

Lai Y, Eulgem T. 2018. Transcript-level expression control of plant NLR genes. Mol. Plant Pathol. 19:1267I28I.

Langmead B, Salzberg SL. 2012. Fast gapped-read alignment with Bowtie 2. Nat. Methods 9:357-359.

Larsson A. 20 I4. AliView: a fast and lightweight alignment viewer and editor for large datasets. Bioinformatics 30:3276-3278.

Leister D. 2004. Tandem and segmental gene duplication and recombination in the evolution of plant disease resistance gene. Trends Genet. 20:116-122.

Letunic I, Bork P. 2007. Interactive Tree Of Life (iTOL): an online tool for phylogenetic tree display and annotation. Bioinformatics 23:127-128.

Li B, Dewey CN. 20I I. RSEM: accurate transcript quantification from RNA-Seq data with or without a reference genome. BMC Bioinformatics 12:323.

Li F, Pignatta D, Bendix C, Brunkard JO, Cohn MM, Tung J, Sun H, Kumar P, Baker B. 20I2. MicroRNA regulation of plant innate immune receptors. PNAS 109:1790-1795.

Li H. 20I3. Aligning sequence reads, clone sequences and assembly contigs with BWA-MEM. arXiv I303.3997

Li L, Habring A, Wang K, Weigel D. 2020. Atypical Resistance Protein RPW8/HR Triggers Oligomerization of the NLR Immune Receptor RPP7 and Autoimmunity. Cell Host Microbe 27 (3):405-4I 7

Linthorst J, Hulsman M, Holstege H, Reinders M. 20I5. Scalable multi whole-genome alignment using recursive exact matching. bioRxiv 022715.

$\mathrm{Li}$ Y, Pennington BO, Hua J. 2009. Multiple R-like genes are negatively regulated by BONI and BON3 in arabidopsis. Mol. Plant. Microbe. Interact. 22:840-848.

Love MI, Huber W, Anders S. 2014. Moderated estimation of fold change and dispersion for RNA-seq data with DESeq2. Genome Biol. 15:550.

Lynch M, Conery JS. 2000. The evolutionary fate and consequences of duplicate genes. Science 290:II5I-II55.

Mackey D, Belkhadir Y, Alonso JM, Ecker JR, Dangl JL. 2003. Arabidopsis RIN4 is a target of the type III virulence effector AvrRpt2 and modulates RPS2-mediated resistance. Cell II 2:379-389.

MacQueen A, Bergelson J. 2016. Modulation of R-gene expression across environments. J. Exp. Bot. 67:20932105.

MacQueen A, Sun X, Bergelson J. 2016. Genetic architecture and pleiotropy shape costs of Rps2-mediated resistance in Arabidopsis thaliana. Nat Plants 2:16110.

Maekawa T, Kufer TA, Schulze-Lefert P. 20I I. NLR functions in plant and animal immune systems: so far and yet so close. Nat. Immunol. 12:8I7-826.

Marchal C, Zhang J, Zhang P, Fenwick P, Steuernagel B, Adamski NM, Boyd L, Mclntosh R, Wulff BBH, Berry S, et al. 2018. BED-domain-containing immune receptors confer diverse resistance spectra to yellow rust. Nat Plants 4:662-668.

Mauricio R, Stahl EA, Korves T, Tian D, Kreitman M, Bergelson J. 2003. Natural selection for polymorphism in the disease resistance gene Rps2 of Arabidopsis thaliana. Genetics 163:735-746.

McDowell JM, Cuzick A, Can C, Beynon J, Dangl JL, Holub EB. 2000. Downy mildew (Peronospora parasitica) resistance genes in Arabidopsis vary in functional requirements for NDRI, EDSI, NPRI and salicylic acid accumulation. Plant J. 22:523-529. 
bioRxiv preprint doi: https://doi.org/10.1101/2020.05.18.101451; this version posted May 20, 2020. The copyright holder for this preprint (which was not certified by peer review) is the author/funder, who has granted bioRxiv a license to display the preprint in perpetuity. It is made available under aCC-BY 4.0 International license.

Barragan et al. Relocated singleton NLR and hybrid necrosis

McKenna A, Hanna M, Banks E, Sivachenko A, Cibulskis K, Kernytsky A, Garimella K, Altshuler D, Gabriel S, Daly M, et al. 2010. The Genome Analysis Toolkit: a MapReduce framework for analyzing next-generation DNA sequencing data. Genome Res. 20:1297-1303.

Meyers BC, Kaushik S, Nandety RS. 2005. Evolving disease resistance genes. Curr. Opin. Plant Biol. 8:I29-I34.

Meyers BC, Kozik A, Griego A, Kuang H, Michelmore RW. 2003. Genome-wide analysis of NBS-LRR-encoding genes in Arabidopsis. Plant Cell 15:809-834.

Michelmore RW, Meyers BC. 1998. Clusters of resistance genes in plants evolve by divergent selection and a birth-and-death process. Genome Res. 8:1 II3-II30.

Mine A, Seyfferth C, Kracher B, Berens ML, Becker D, Tsuda K. 2018. The Defense Phytohormone Signaling Network Enables Rapid, High-Amplitude Transcriptional Reprogramming during Effector-Triggered Immunity. Plant Cell 30:1199-1219.

Mohr TJ, Mammarella ND, Hoff T, Woffenden BJ, Jelesko JG, McDowell JM. 2010. The Arabidopsis downy mildew resistance gene RPP8 is induced by pathogens and salicylic acid and is regulated by $\mathrm{W}$ box cis elements. Mol. Plant. Microbe. Interact. 23:1303-I3I5.

Mondragón-Palomino M, Meyers BC, Michelmore RW, Gaut BS. 2002. Patterns of positive selection in the complete NBS-LRR gene family of Arabidopsis thaliana. Genome Res. 12:1305-1315.

Nei M, Gojobori T. 1986. Simple methods for estimating the numbers of synonymous and nonsynonymous nucleotide substitutions. Mol. Biol. Evol. 3:4I8-426.

Nishimura MT, Anderson RG, Cherkis KA, Law TF, Liu QL, Machius M, Nimchuk ZL, Yang L, Chung E-H, El Kasmi F, et al. 20I7. TIR-only protein RBAI recognizes a pathogen effector to regulate cell death in Arabidopsis. PNAS. II4:E2053-E2062.

Ohno S. 1970. Evolution by Gene Duplication. Springer, Berlin, Heidelberg

Palma K, Thorgrimsen S, Malinovsky FG, Fiil BK, Nielsen HB, Brodersen P, Hofius D, Petersen M, Mundy J. 2010. Autoimmunity in Arabidopsis acd II is mediated by epigenetic regulation of an immune receptor. PLoS Pathog. 6:el00II37.

Pandey SP, Somssich IE. 2009. The role of WRKY transcription factors in plant immunity. Plant Physiol. 150:1648-1655.

Papadopoulou GV, Maedicke A, Grosser K, van Dam NM, Martínez-Medina A. 20I8. Defence signalling marker gene responses to hormonal elicitation differ between roots and shoots. AoB Plants I0:ly03 I.

Patterson N, Price AL, Reich D. 2006. Population structure and eigenanalysis. PLoS Genet. 2:el 90.

Picó FX, Méndez-Vigo B, Martínez-Zapater JM, Alonso-Blanco C. 2008. Natural genetic variation of Arabidopsis thaliana is geographically structured in the Iberian peninsula. Genetics 180:1009-1021.

Purcell S, Neale B, Todd-Brown K, Thomas L, Ferreira MAR, Bender D, Maller J, Sklar P, de Bakker PIW, Daly MJ, et al. 2007. PLINK: a tool set for whole-genome association and population-based linkage analyses.

Am. J. Hum. Genet. 81:559-575.

Ribot C, Hirsch J, Balzergue S, Tharreau D, Nottéghem J-L, Lebrun M-H, Morel J-B. 2008. Susceptibility of rice to the blast fungus, Magnaporthe grisea. J. Plant Physiol. 165:I I4-124.

Richly E, Kurth J, Leister D. 2002. Mode of amplification and reorganization of resistance genes during recent Arabidopsis thaliana evolution. Mol. Biol. Evol. 19:76-84.

Roth C, Lüdke D, Klenke M, Quathamer A, Valerius O, Braus GH, Wiermer M. 2017. The truncated NLR protein TIR-NBSI 3 is a MOS6/IMPORTIN- $\alpha 3$ interaction partner required for plant immunity. Plant J. 92:808-821.

Rowan BA, Seymour DK, Chae E, Lundberg DS, Weigel D. 2017. Methods for Genotyping-by-Sequencing. Methods Mol. Biol. 1492:22I-242.

Ruggieri V, Nunziata A, Barone A. 2014. Positive selection in the leucine-rich repeat domain of Grol genes in Solanum species. J. Genet. 93:755-765.

Schwab R, Ossowski S, Riester M, Warthmann N, Weigel D. 2006. Highly specific gene silencing by artificial microRNAs in Arabidopsis. Plant Cell 18:1121-1133.

Shao Z-Q, Xue J-Y, Wu P, Zhang Y-M, Wu Y, Hang Y-Y, Wang B, Chen J-Q. 20I6. Large-Scale Analyses of Angiosperm Nucleotide-Binding Site-Leucine-Rich Repeat Genes Reveal Three Anciently Diverged Classes with Distinct Evolutionary Patterns. Plant Physiol. 170:2095-2 109. 
bioRxiv preprint doi: https://doi.org/10.1101/2020.05.18.101451; this version posted May 20, 2020. The copyright holder for this preprint (which was not certified by peer review) is the author/funder, who has granted bioRxiv a license to display the preprint in perpetuity. It is made available under aCC-BY 4.0 International license.

Barragan et al. Relocated singleton NLR and hybrid necrosis

Shirano Y, Kachroo P, Shah J, Klessig DF. 2002. A gain-of-function mutation in an Arabidopsis Toll Interleukin I receptor-nucleotide binding site-leucine-rich repeat type $R$ gene triggers defense responses and results in enhanced disease resistance. Plant Cell I4:3 I49-3162.

Shivaprasad PV, Chen H-M, Patel K, Bond DM, Santos BACM, Baulcombe DC. 2012. A microRNA superfamily regulates nucleotide binding site-leucine-rich repeats and other mRNAs. Plant Cell 24:859-874.

Sicard A, Kappel C, Josephs EB, Lee YW, Marona C, Stinchcombe JR, Wright SI, Lenhard M. 20I5. Divergent sorting of a balanced ancestral polymorphism underlies the establishment of gene-flow barriers in Capsella. Nat. Commun. 6:7960.

Sohn KH, Segonzac C, Rallapalli G, Sarris PF, Woo JY, Williams SJ, Newman TE, Paek KH, Kobe B, Jones JDG. 2014. The nuclear immune receptor RPS4 is required for RRSISLHI-dependent constitutive defense activation in Arabidopsis thaliana. PLoS Genet. 10:e 1004655.

Staal J, Kaliff M, Bohman S, Dixelius C. 2006. Transgressive segregation reveals two Arabidopsis TIR-NB-LRR resistance genes effective against Leptosphaeria maculans, causal agent of blackleg disease. Plant J. 46:218230.

Stahl EA, Dwyer G, Mauricio R, Kreitman M, Bergelson J. 1999. Dynamics of disease resistance polymorphism at the Rpm I locus of Arabidopsis. Nature 400:667-67I.

Stamatakis A. 2014. RAxML version 8: a tool for phylogenetic analysis and post-analysis of large phylogenies. Bioinformatics 30:1312-1313.

Stanke M, Schöffmann O, Morgenstern B, Waack S. 2006. Gene prediction in eukaryotes with a generalized hidden Markov model that uses hints from external sources. BMC Bioinformatics 7:62.

Steinbrenner AD, Goritschnig S, Staskawicz BJ. 20I5. Recognition and activation domains contribute to allelespecific responses of an Arabidopsis NLR receptor to an oomycete effector protein. PLoS Pathog. I I:el004665.

Stokes TL, Kunkel BN, Richards EJ. 2002. Epigenetic variation in Arabidopsis disease resistance. Genes Dev. 16:171-182.

Sueldo DJ, Shimels M, Spiridon LN, Caldararu O, Petrescu A-J, Joosten MHAJ, Tameling WIL. 20I5. Random mutagenesis of the nucleotide-binding domain of NRCI (NB-LRR Required for Hypersensitive ResponseAssociated Cell Death-I), a downstream signalling nucleotide-binding, leucine-rich repeat (NB-LRR) protein, identifies gain-of-function mutations in the nucleotide-binding pocket. New Phytol. 208:210-223.

Supek F, Bošnjak M, Škunca N, Šmuc T. 20II. REVIGO summarizes and visualizes long lists of gene ontology terms. PLoS One 6:e21800.

Świadek M, Proost S, Sieh D, Yu J, Todesco M, Jorzig C, Rodriguez Cubillos AE, Plötner B, Nikoloski Z, Chae E, et al. 2017. Novel allelic variants in ACD6 cause hybrid necrosis in local collection of Arabidopsis thaliana. New Phytol. 213:900-915.

Swiderski MR, Birker D, Jones JDG. 2009. The TIR domain of TIR-NB-LRR resistance proteins is a signaling domain involved in cell death induction. Mol. Plant. Microbe. Interact. 22:157-165.

Tameling WIL, Elzinga SDJ, Darmin PS, Vossen JH, Takken FLW, Haring MA, Cornelissen BJC. 2002. The tomato R gene products I-2 and MI-I are functional ATP binding proteins with ATPase activity. Plant Cell 14:2929-2939.

Tan X, Meyers BC, Kozik A, West MAL, Morgante M, St Clair DA, Bent AF, Michelmore RW. 2007. Global expression analysis of nucleotide binding site-leucine rich repeat-encoding and related genes in Arabidopsis. BMC Plant Biol. 7:56.

Tian T, Liu Y, Yan H, You Q, Yi X, Du Z, Xu W, Su Z. 2017. agriGO v2.0: a GO analysis toolkit for the agricultural community, 2017 update. Nucleic Acids Res. 45:WI22-WI29.

Todesco M, Kim S-T, Chae E, Bomblies K, Zaidem M, Smith LM, Weigel D, Laitinen RAE. 20I4. Activation of the Arabidopsis thaliana immune system by combinations of common ACD6 alleles. PLoS Genet. I0:el004459.

Tsuchiya T, Eulgem T. 2013. An alternative polyadenylation mechanism coopted to the Arabidopsis RPP7 gene through intronic retrotransposon domestication. PNAS I I0:E3535-E3543.

Van de Weyer A-L, Monteiro F, Furzer OJ, Nishimura MT, Cevik V, Witek K, Jones JDG, DangI JL, Weigel D, Bemm F. 2019. A Species-Wide Inventory of NLR Genes and Alleles in Arabidopsis thaliana. Cell 
bioRxiv preprint doi: https://doi.org/10.1101/2020.05.18.101451; this version posted May 20, 2020. The copyright holder for this preprint (which was not certified by peer review) is the author/funder, who has granted bioRxiv a license to display the preprint in perpetuity. It is made available under aCC-BY 4.0 International license.

Barragan et al. Relocated singleton NLR and hybrid necrosis

178:1260-1272.el4.

Walker BJ, Abeel T, Shea T, Priest M, Abouelliel A, Sakthikumar S, Cuomo CA, Zeng Q, Wortman J, Young SK, et al. 20I4. Pilon: an integrated tool for comprehensive microbial variant detection and genome assembly improvement. PLoS One 9:el 12963.

Wang D, Zhang Y, Zhang Z, Zhu J, Yu J. 2010. KaKs_Calculator 2.0: a toolkit incorporating gamma-series methods and sliding window strategies. Genomics Proteomics Bioinformatics 8:77-80.

Wang G-F, Ji J, El-Kasmi F, Dangl JL, Johal G, Balint-Kurti PJ. 20I5. Molecular and functional analyses of a maize autoactive NB-LRR protein identify precise structural requirements for activity. PLoS Pathog. II:el 004674.

Weigel D, Glazebrook J. 2002. Arabidopsis: a laboratory manual. CSHL Press

Wicker T, Yahiaoui N, Keller B. 2007. Illegitimate recombination is a major evolutionary mechanism for initiating size variation in plant resistance genes. Plant J. 5I:63I-64I.

Wickham H. 2009. Ggplot2: Elegant Graphics for Data Analysis. 2nd ed. Springer Publishing Company, Incorporated

Williams SJ, Sornaraj P, deCourcy-Ireland E, Menz RI, Kobe B, Ellis JG, Dodds PN, Anderson PA. 20I I. An autoactive mutant of the $M$ flax rust resistance protein has a preference for binding ATP, whereas wildtype M protein binds ADP. Mol. Plant. Microbe. Interact. 24:897-906.

Wong S, Wolfe KH. 2005. Birth of a metabolic gene cluster in yeast by adaptive gene relocation. Nat. Genet. 37:777-782.

Workman R, Timp W, Fedak R, Kilburn D, Hao S, Liu K. 2018. High molecular weight DNA extraction from recalcitrant plant species for third generation sequencing. Protocol Exchange: I-I2. Available from: http://dx.doi.org/ 10.1038/protex.2018.059

Xia R, Xu J, Arikit S, Meyers BC. 2015. Extensive Families of miRNAs and PHAS Loci in Norway Spruce Demonstrate the Origins of Complex phasiRNA Networks in Seed Plants. Mol. Biol. Evol. 32:2905-2918.

Yaffe H, Buxdorf K, Shapira I, Ein-Gedi S, Moyal-Ben Zvi M, Fridman E, Moshelion M, Levy M. 20I2. LogSpin: a simple, economical and fast method for RNA isolation from infected or healthy plants and other eukaryotic tissues. BMC Res. Notes 5:45.

Yamamoto E, Takashi T, Morinaka Y, Lin S, Wu J, Matsumoto T, Kitano H, Matsuoka M, Ashikari M. 20I 0. Gain of deleterious function causes an autoimmune response and Bateson-Dobzhansky-Muller incompatibility in rice. Mol. Genet. Genomics 283:305-315.

Yang S, Hua J. 2004. A haplotype-specific Resistance gene regulated by BONZAII mediates temperaturedependent growth control in Arabidopsis. Plant Cell 16:1060-107I.

Yi H, Richards Ej. 2007. A Cluster of Disease Resistance Genes in Arabidopsis Is Coordinately Regulated by Transcriptional Activation and RNA Silencing. Plant Cell 19:2929-2939.

Yu A, Lepère G, Jay F, Wang J, Bapaume L, Wang Y, Abraham A-L, Penterman J, Fischer RL, Voinnet O, et al. 2013. Dynamics and biological relevance of DNA demethylation in Arabidopsis antibacterial defense. PNAS. I 1 0:2389-2394.

Zhai J, Jeong D-H, De Paoli E, Park S, Rosen BD, Li Y, González AJ, Yan Z, Kitto SL, Grusak MA, et al. 201 I. MicroRNAs as master regulators of the plant NB-LRR defense gene family via the production of phased, trans-acting siRNAs. Genes Dev. 25:2540-2553.

Zhang Y, Wang Y, Liu J, Ding Y, Wang S, Zhang X, Liu Y, Yang S. 2017. Temperature-dependent autoimmunity mediated by chs I requires its neighboring TNL gene SOC3. New Phytol. 2I 3:1330-1345.

Zhao T, Rui L, Li J, Nishimura MT, Vogel JP, Liu N, Liu S, Zhao Y, Dangl JL, Tang D. 20I5. A truncated NLR protein, TIR-NBS2, is required for activated defense responses in the exo70BI mutant. PLoS Genet. I I:el004945.

Zheng X, Pontes O, Zhu J, Miki D, Zhang F, Li W-X, lida K, Kapoor A, Pikaard CS, Zhu J-K. 2008. ROS3 is an RNA-binding protein required for DNA demethylation in Arabidopsis. Nature 455:1259-1262.

Zipfel C, Robatzek S, Navarro L, Oakeley EJ, Jones JDG, Felix G, Boller T. 2004. Bacterial disease resistance in Arabidopsis through flagellin perception. Nature 428:764-767. 